\title{
Efficacy and Safety of Non-Vitamin K Anticoagulants for Atrial Fibrillation in Relation to Different Renal Function Levels: A Network Meta-Analysis
}

\author{
Hao Jin $\left(\mathbb{D},{ }^{1}\right.$ Kongbo Zhu $\left(\mathbb{D},{ }^{1}\right.$ Lina Wang $\left(\mathbb{D},{ }^{2}\right.$ Yifan Li $\left(\mathbb{D},{ }^{1}\right.$ \\ Jingjun Meng $\mathbb{D}^{1}$, and Hong Zhi $\mathbb{C}^{1}$ \\ ${ }^{1}$ Department of Cardiology, Affiliated ZhongDa Hospital of Southeast University (HZ), Nanjing 210009, China \\ ${ }^{2}$ Department of Epidemiology and Biostatistics, School of Public Health, Southeast University, Nanjing 210009, China \\ Correspondence should be addressed to Hong Zhi; 101005674@seu.edu.cn
}

Received 12 November 2019; Accepted 29 January 2020; Published 25 April 2020

Academic Editor: Pawel Ptaszynski

Copyright (C) 2020 Hao Jin et al. This is an open access article distributed under the Creative Commons Attribution License, which permits unrestricted use, distribution, and reproduction in any medium, provided the original work is properly cited.

\begin{abstract}
Background. We performed a network meta-analysis (NMA) comparing the efficacy (stroke or systemic embolism) and safety (major bleeding) among different non-vitamin $\mathrm{K}$ antagonist oral anticoagulants (NOACs) in patients with atrial fibrillation (AF) and renal impairment, with the aim of recommending the proper drug and the dose based on renal function. Methods. We searched PubMed, EMBASE, Web of Science, and Cochrane Library with the items "dabigatran, edoxaban, apixaban, rivaroxaban, warfarin, and atrial fibrillation" through August 2019. NMA was analyzed with R (version 3.5.1, R Foundation for Statistical Computing) with the packages gemtc recalling JAGS (version 4.3.0) for the efficacy and safety of each drug with regard to different levels of renal function. NetMetaXL (version 1.6.1) and winBUGS (version 1.4.3) were used to obtain the cumulative ranking curve (SUCRA) of each drug. Result. In patients with normal renal function, dabigatran150 was ranked as the most effective drug (SUCRA 0.90), followed by dabigatran110 (SUCRA 0.68), apixaban (SUCRA 0.66), and rivaroxaban (SUCRA 0.59). With regard to the safety for preventing major bleeding, there was high probability that edoxaban30 (SUCRA 0.99) ranked first, compared to dabigatran110 (SUCRA 0.78) and edoxaban60 (SUCRA 0.66). For patients with mild renal impairment, with respect to the most effective drug for preventing stroke or systemic embolism, edoxaban60 ranked first (SUCRA 0.98), in comparison with dabigatran150 (SUCRA 0.74) and apixaban (SUCRA 0.64). Possibility of ranking first for the safest drug was edoxaban30 (SUCRA 0.99), followed by dabigatran110 (SUCRA 0.70) and apixaban (SUCRA 0.69). In patients with moderate renal function, dabigatran150 (SUCRA 0.95) ranked as the most effective drug in comparison with apixaban (SUCRA 0.66). Dabigatran110 (SUCRA 0.53), rivaroxaban (SUCRA 0.51), and edoxaban60 (SUCRA 0.50) had the similar probability of ranking third. When referred to the safest drug, probability of ranking first for preventing major bleeding was edoxaban30 (SUCRA 0.98), followed by apixaban (SUCRA 0.85) and edoxaban60 (SUCRA 0.64). Conclusion. In patients with AF and renal impairment and for patients with normal renal function, dabigatran $110 \mathrm{mg}$ (bid) might have a better effect on the clinical results. And it does not coincide with patients taking dabigatran $110 \mathrm{mg}$ with dose reduction for other factors including aged $\geq 75$ years, renal impairment (CrCL $30-50 \mathrm{~mL} / \mathrm{min}$ ), gastritis, esophagitis, or gastroesophageal reflux, receiving concomitant verapamil, and so on. For patients with mild renal impairment, apixaban $5 \mathrm{mg}$ (bid) would be a better choice for preventing stroke or systemic embolism and major bleeding, while apixaban $5 \mathrm{mg}$ (bid) and edoxaban $60 \mathrm{mg}$ (qd) were recommended for patients with moderate renal impairment. However, considering the fact of no RCTs for the head-to-head comparison, caution should be exercised over selecting each of NOACs for patients.
\end{abstract}

\section{Introduction}

As was shown in a recent survey published in China at the national level, the standardized overall prevalence of atrial fibrillation (AF) among the Chinese adults aged $\geq 40$ years was $2.31 \%$ (95\% CI: $2.28-2.33 \%)$. Additionally, there was a higher probability that participants with AF would have a stroke than those without AF $(9.48 \%$ vs $2.26 \%, P<0.001)$ [1]. According to the GARFIELD-AF registry with 2-year follow-up, the percentage $(95 \% \mathrm{CI})$ of all-cause mortality, 
TABLE 1: Search strategy.

\begin{tabular}{lc}
\hline \multicolumn{2}{c}{ Search terms } \\
\hline$\# 1$ & "Atrial fibrillation": ti, ab, kw \\
$\# 2$ & "Auricular fibrillation": ti, ab, kw \\
$\# 3$ & $\# 1$ or \#2 \\
$\# 4$ & Dabigatran:ti, ab, kw \\
$\# 5$ & apixaban: ti, ab, kw \\
$\# 6$ & Rivaroxaban: ti, ab, kw \\
$\# 7$ & Edoxaban: ti, ab, kw \\
$\# 8$ & (Thrombin inhibit*): ti, ab, kw \\
$\# 9$ & (Factor next xa next inhibit*): ti, ab, kw \\
$\# 10$ & Or/\#4-\#9 \\
$\# 11$ & $\# 3$ and \#10 \\
\hline
\end{tabular}

stroke or systemic embolism, and major bleeding (first occurrences) was 3.84 (3.68; 4.02), $1.27(1.18 ; 1.38)$, and 0.71 $(0.64,0.79)$ per 100 person-years [2].

The data from the German AFNET (German Competence Network on Atrial Fibrillation) database conveyed the message that paroxysmal AF was often accompanied by chronic kidney diseases (CKD) $(48.7 \%$ vs. $35.6 \%$ in CKD stages 4 and 5) and permanent AF was also more common in CKD (35.5\% and 37.3\% CKD stages 4 and 5), meaning that $\mathrm{AF}$ and $\mathrm{CKD}$ often coexist [3]. In patients with $\mathrm{AF}$ and renal impairment, the risk of 12-month recurrent stroke and death had increased in comparison to the patients with AF or CKD alone [4]. In the course of a long time, warfarin was used for the prevention of stroke of patients with AF, which had played a crucial role in anticoagulant therapy. Nevertheless, it did have some limitations for narrow therapeutic window, food interactions, necessary monitoring, and dose adjustments [5]. In light of these drawbacks, four large randomized phase III trials (RE-LY [6], ROCKET-AF [7], ARISTOTLE [8], and ENGAGE AF-TIMI 48 [9]) were performed to compare the safety and efficacy between warfarin and nonvitamin K antagonist oral anticoagulants (NOACs). The four trials had presented the results that in terms of stroke or systemic embolism, rivaroxaban, edoxaban, dabigatran $150 \mathrm{mg}$, and apixaban were noninferior to warfarin. In respect to the risk of major bleeding, rivaroxaban and dabigatran $150 \mathrm{mg}$ were not associated with lower rates in comparison to warfarin, while edoxaban and apixaban tended to reduce the risk. Additionally, there was no difference between dabigatran $110 \mathrm{mg}$ and warfarin. As a result, these four NOACs had been approved for the prevention of stroke or systemic and major bleeding in patients with $\mathrm{AF}$ and served as an alternative to vitamin $\mathrm{K}$ antagonists (VKAs) [10]. However, these four NOACs all had a different degree of renal elimination, with dabigatran $80 \%$, edoxaban $50 \%$, rivaroxaban $35 \%$, and apixaban $27 \%$ [11]. As a consequence, the proper drug and dose should be estimated according to the renal function before the patients accept the anticoagulant therapy [12]. Recently, the meta-analysis had evaluated the efficacy and safety between the NOACs and VKA for anticoagulation in AF based on renal function. The result illustrated that NOACs would reduce the risk of stroke or systemic embolism and major bleeding in respect to different levels of renal function $[13,14]$. Additionally, network meta- analysis (NMA) was also performed to compare the efficacy and safety among different NOACs, finding that apixaban would be a better choice with regard to preventing stroke or systemic embolism and major bleeding in comparison to the other NOACs [15]. However, comparing NOACS to VKA made no contributions to choosing the applicable drug for anticoagulation as the lack of head-to-head comparison in relation to renal function, including the indirect comparison without the analysis on subgroups of patients with different renal functions. One NMA just assessed the anticoagulation in patients with moderate $\mathrm{CKD}$ of $\mathrm{AF}$ [16], while paying little attention to patient with different levels of renal function. As a consequence, with the influence of different NOACs and renal function levels on anticoagulation taken into consideration to compare the efficacy and safety in patients with $\mathrm{AF}$, we performed the NMA to find the proper NOAC and its dose for patients with the specific renal function.

\section{Methods}

2.1. Data Search. We searched the RCTs comparing the effect of NOACs preventing stroke or systemic embolism and major bleeding in patients with $\mathrm{AF}$ and different levels of renal function. We searched PubMed, EMBASE, Web of Science, and Cochrane Library with the items "dabigatran, edoxaban, apixaban, rivaroxaban, warfarin, and atrial fibrillation" through August 2019 (Table 1).

2.2. Selection Criteria. Each study was reviewed by two authors independently. When coming up with disagreements during the process, we asked for another author for help if necessary. One study included in our article had to meet the following criteria: (1) it had to be a phase III or IV randomized trial, comparing NOACs (dabigatran, rivaroxaban, apixaban, or edoxaban) with warfarin in patients with AF. (2) The patients with different renal function ought to be known and the outcome of efficacy and safety (stroke and major bleeding) should be reported based on the renal function. We selected the latest and most complete data when facing different study reporting the same trial.

2.3. Assessment of Risk of Bias. The bias of the study was assessed using Cochrane Collaboration Risk of Bias Tool (Higgins 2011), as follows: random sequence generation, allocation concealment, blinding of participants and personnel, blinding of outcome assessment, incomplete outcome data, selective reporting, and other bias.

2.4. Data Extraction. Information extracted ought to include the study design, the type of NOACs and the dose regimens, patients, median age, type of the $\mathrm{AF}$, mean or median CHADS2, previous stroke, and other information about the characteristics of patients. Primary efficacy outcome was stroke or systemic embolism and primary safety outcome was major bleeding, the definitions of which were extracted from the trials. Data of the clinical outcomes was based on renal function, which was categorized using the Cockcorft- 


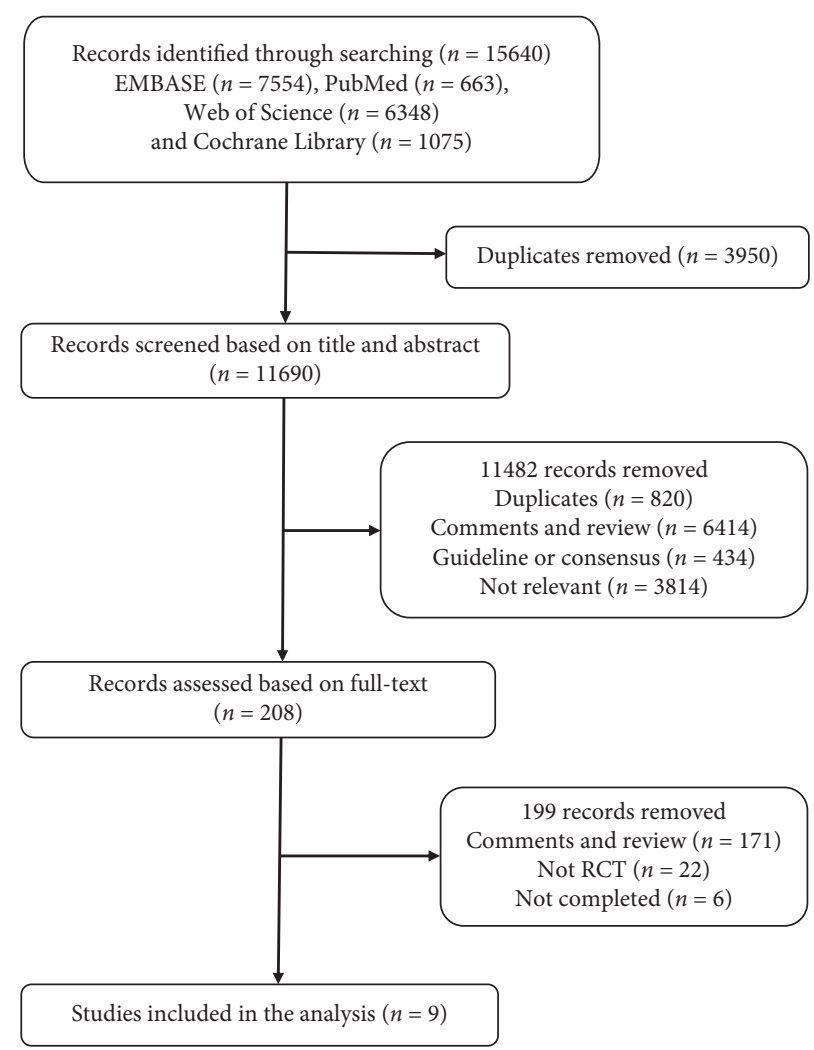

FIGURE 1: Flow diagram of the clinical trial selection process.

TABle 2: Assessment of risk of bias.

\begin{tabular}{|c|c|c|c|c|c|c|c|}
\hline & $\begin{array}{l}\text { Random sequence } \\
\text { generation } \\
\text { (selection bias) }\end{array}$ & $\begin{array}{l}\text { Allocation } \\
\text { concealment } \\
\text { (selection } \\
\text { bias) }\end{array}$ & $\begin{array}{c}\text { Blinding of } \\
\text { participants } \\
\text { and personnel } \\
\text { (performance bias) }\end{array}$ & $\begin{array}{c}\text { Blinding of outcome } \\
\text { assessment } \\
\text { (detection bias) }\end{array}$ & $\begin{array}{l}\text { Incomplete } \\
\text { outcome data } \\
\text { (attrition } \\
\text { bias) }\end{array}$ & $\begin{array}{l}\text { Selective } \\
\text { reporting } \\
\text { (reporting } \\
\text { bias) }\end{array}$ & $\begin{array}{c}\text { Other } \\
\text { bias }\end{array}$ \\
\hline RE-LY & Low & Low & Unclear & Low & Low & Low & Low \\
\hline ARISTOTLE & Low & Low & Low & Low & Low & Low & Low \\
\hline ROCKET-AF & Low & Low & Low & Low & Low & Low & Low \\
\hline $\begin{array}{l}\text { ENGAGE AF- } \\
\text { TIMI } 48\end{array}$ & Low & Low & Low & Low & Low & Low & Low \\
\hline
\end{tabular}

TABLE 3: Characteristics of the included trials.

\begin{tabular}{|c|c|c|c|c|c|c|c|c|c|c|}
\hline \multirow[b]{2}{*}{ Dosing regiments } & \multicolumn{3}{|c|}{ RE-LY (18113) } & \multicolumn{2}{|c|}{$\begin{array}{l}\text { ARISTOTLE } \\
(18201)\end{array}$} & \multicolumn{2}{|c|}{$\begin{array}{c}\text { ROCKET-AF } \\
(14262)\end{array}$} & \multicolumn{3}{|c|}{ ENGAGE AF 48 (21105) } \\
\hline & $\begin{array}{c}110 \mathrm{mg} \\
\text { bid }\end{array}$ & $\begin{array}{c}150 \mathrm{mg} \\
\text { bid }\end{array}$ & Adjusted & $\begin{array}{l}5 \mathrm{mg} \\
\text { bid }^{(1)}\end{array}$ & Adjusted & $\begin{array}{c}20 \mathrm{mg} \\
\mathrm{qd}^{(2)}\end{array}$ & Adjusted & $\begin{array}{c}30 \mathrm{mg} \\
\mathrm{qd}^{(3)}\end{array}$ & $\begin{array}{l}60 \mathrm{mg} \\
\mathrm{qd}^{(4)}\end{array}$ & Adjusted \\
\hline Median age, years & 71.4 & 71.5 & 71.6 & 70 & 70 & 73 & 73 & 72 & 72 & 72 \\
\hline \multicolumn{11}{|l|}{ Type of AF, \% } \\
\hline Paroxysmal & 32.1 & 32.6 & 33.8 & 15.1 & 15.5 & 17.5 & 17.8 & 25.3 & 24.9 & 26.1 \\
\hline Persistent, permanent & 67.9 & 67.4 & 66.2 & 84.9 & 84.4 & 81.1 & 80.8 & NR & NR & NR \\
\hline Mean CHADS2 score & 2.1 & 2.2 & 2.1 & 2.1 & 2.1 & 3.5 & 3.5 & 2.8 & 2.8 & 2.8 \\
\hline Previous stroke or TIA,\% & 19.9 & 20.3 & 19.8 & 19.2 & 19.7 & 54.9 & 54.6 & 28.3 & 28.1 & 28.5 \\
\hline Heart failure, $\%$ & 32.2 & 31.8 & 31.9 & 35.5 & 35.4 & 62.6 & 62.3 & 57.5 & 58.2 & 56.6 \\
\hline Diabetes mellitus, \% & 23.4 & 23.1 & 23.4 & 25.0 & 24.9 & 40.4 & 39.5 & 35.8 & 36.4 & 36.2 \\
\hline Hypertension, \% & 78.8 & 78.9 & 78.9 & 87.3 & 87.6 & 90.3 & 90.8 & 93.6 & 93.7 & 93.3 \\
\hline Previous VKA use, \% & 50.1 & 50.2 & 48.6 & 51.7 & 57.2 & 62.3 & 62.5 & 58.8 & 58.8 & 59.2 \\
\hline
\end{tabular}


TABLE 3: Continued.

\begin{tabular}{|c|c|c|c|c|c|c|c|c|c|c|}
\hline \multirow[b]{2}{*}{$\begin{array}{l}\text { Normal renal function, } \% \\
>80 \mathrm{ml} / \mathrm{min}\end{array}$} & \multicolumn{3}{|c|}{ RE-LY (18113) } & \multicolumn{2}{|c|}{$\begin{array}{l}\text { ARISTOTLE } \\
(18201)\end{array}$} & \multicolumn{2}{|c|}{$\begin{array}{l}\text { ROCKET-AF } \\
\quad(14262)\end{array}$} & \multicolumn{3}{|c|}{ ENGAGE AF 48 (21105) } \\
\hline & 32.3 & 32.0 & 32.2 & 41.2 & 41.4 & 32.3 & 31.3 & NR & NR & NR \\
\hline $\begin{array}{l}\text { Mild renal function, } \% \\
(50-80 \mathrm{ml} / \mathrm{min})\end{array}$ & 48.6 & 48.1 & 48.5 & 41.6 & 41.8 & 46.6 & 46.8 & NR & NR & NR \\
\hline $\begin{array}{l}\text { Moderate renal function, \% } \\
(30-50 \mathrm{ml} / \mathrm{min}\end{array}$ & 19.4 & 19.2 & 19.4 & 16.5 & 16.6 & 21.0 & 20.6 & 19.3 & 19.6 & 19.0 \\
\hline Mean follow-up years & 2.0 & 2.0 & 2.0 & 1.8 & 1.8 & 1.9 & 1.9 & 2.8 & 2.8 & 2.8 \\
\hline
\end{tabular}

${ }^{(1)} 2.5 \mathrm{mg}$ bid of patients with two or more of the following criteria: $\geq 80$ years, $\geq 60 \mathrm{~kg}$, or serum creatinine $\geq 1.5 \mathrm{mg} / \mathrm{dl} .{ }^{(2)} 15 \mathrm{mg}$ qd in patients with creatinine clearance: $30-49 \mathrm{ml} / \mathrm{min} .{ }^{(3)} 15 \mathrm{mg}$ qd for patients with any of the following characteristics at the time of randomization or during the study: eGFR: $30-50 \mathrm{ml} / \mathrm{min}$, weight $\leq 60 \mathrm{~kg}$, or the concomitant use of verapamil or quinidine. ${ }^{(4)} 30 \mathrm{mg}$ qd for patients with any of the following characteristics at the time of randomization or during the study: eGFR: 30 to $50 \mathrm{ml} / \mathrm{min}$, weight $\leq 60 \mathrm{~kg}$, or the concomitant use of verapamil or quinidine.
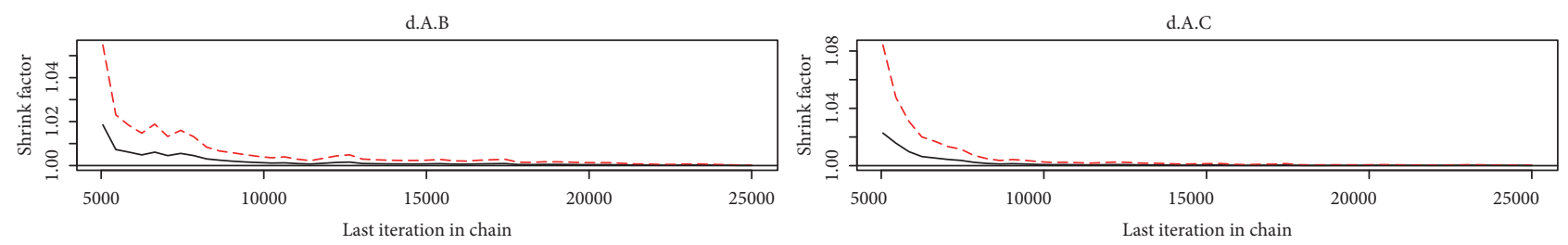

- Median

- Median

$---97.5 \%$
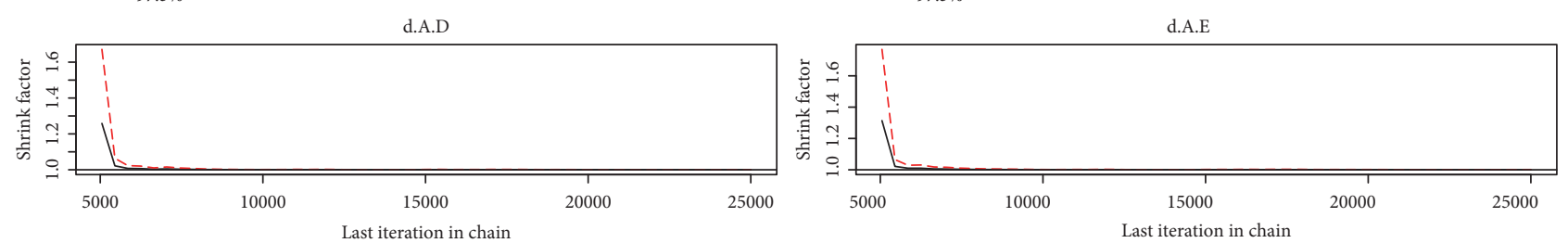

- Median

$---97.5 \%$

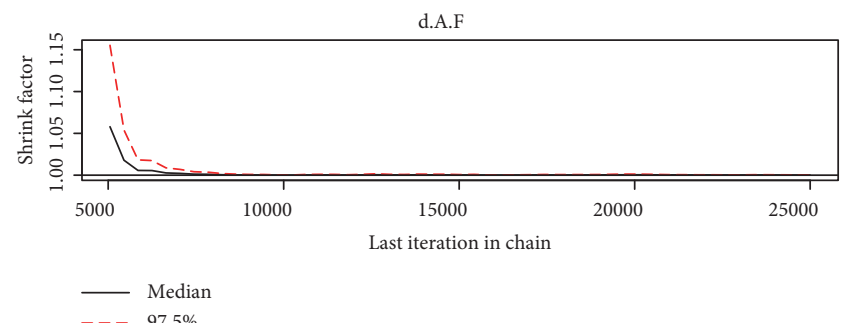

— Median

- - $97.5 \%$

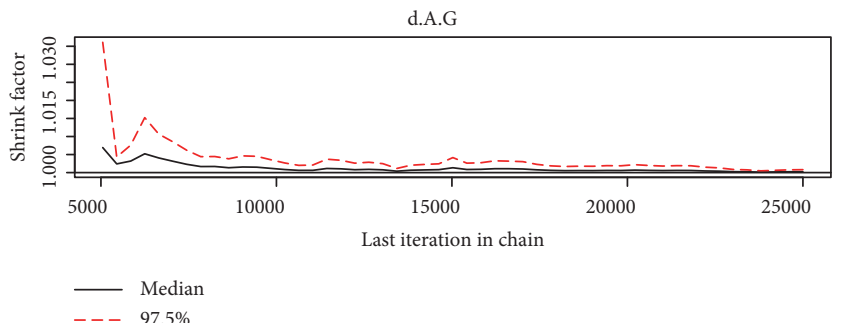

(a)
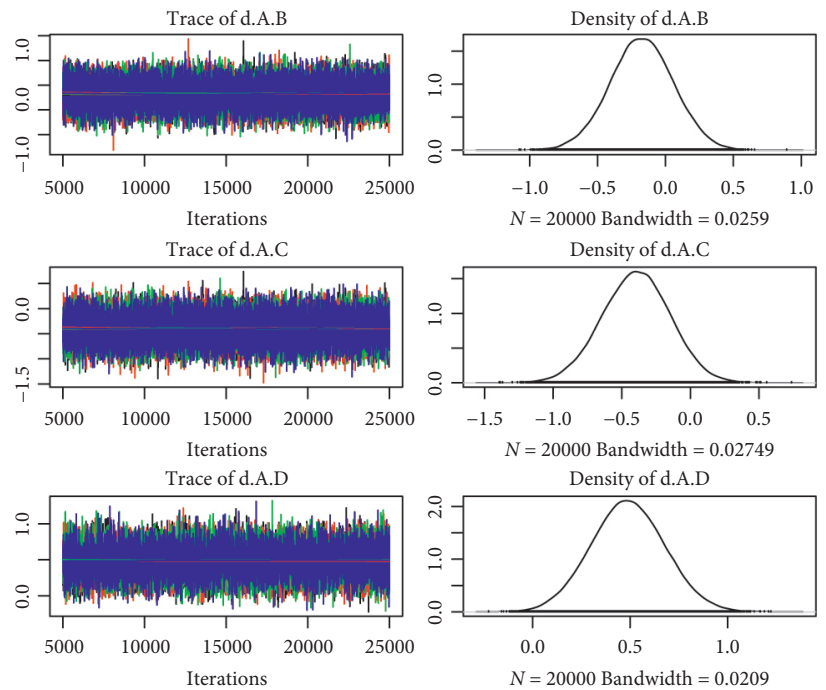

(b)

Figure 2: Continued. 


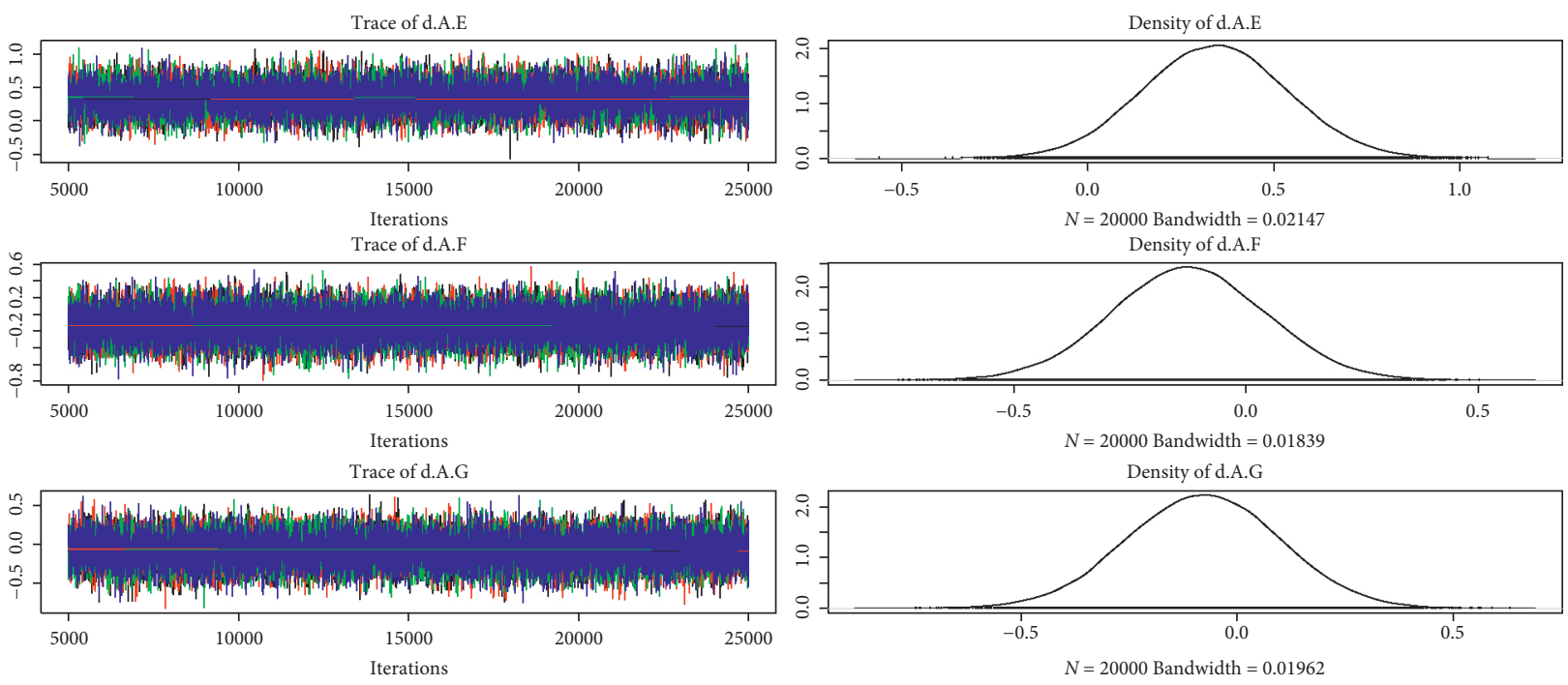

(c)

Figure 2: Brooks-Gelman-Rubin diagnostic plot and density plot for the efficacy of the comparison among different treatments of patients with normal renal function (A: warfarin; B: dabigatran110; C: dabigatran150; D: edoxaban30; E: edoxaban60; F:apixaban; G:rivaroxaban).
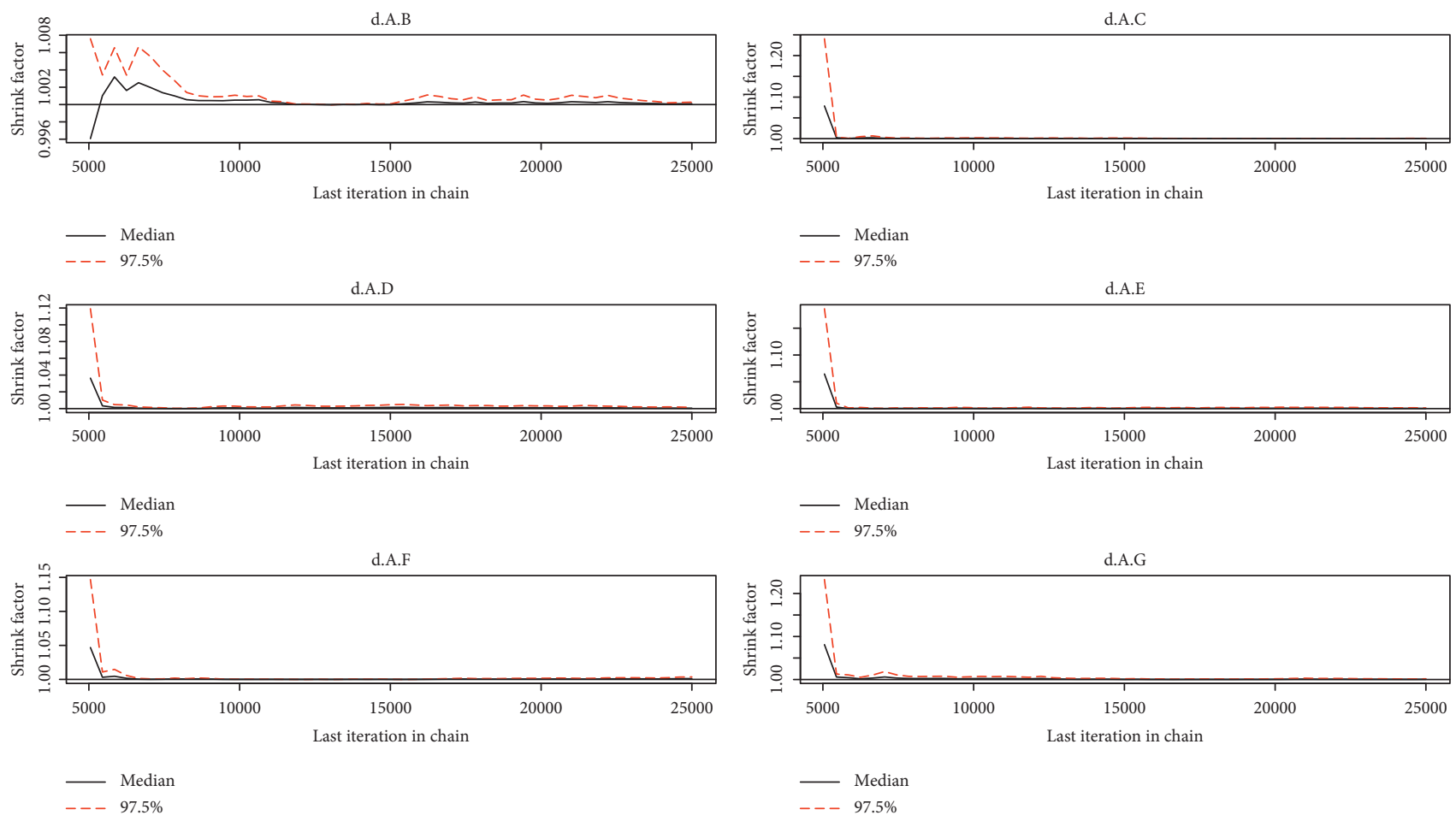

(a)

Figure 3: Continued. 

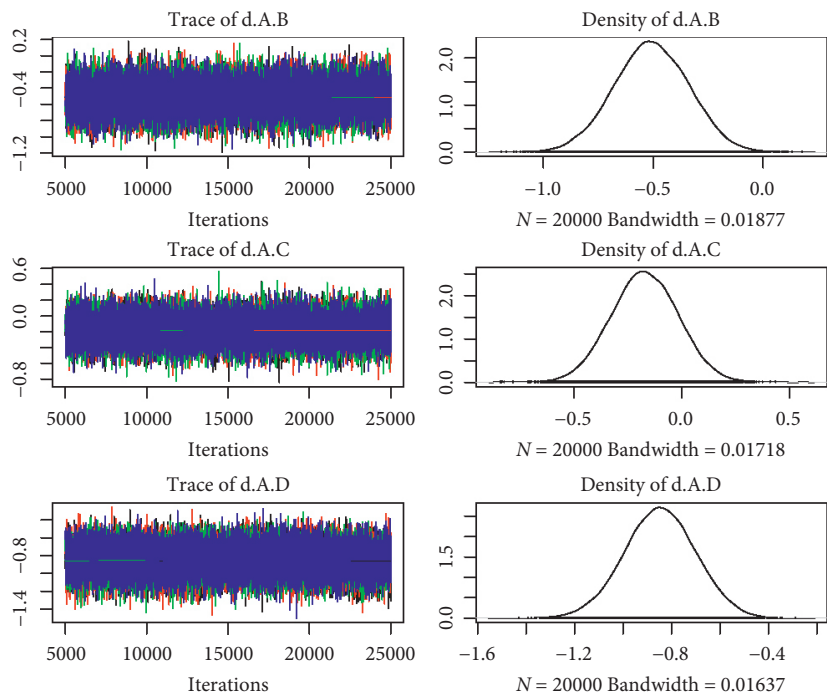

(b)
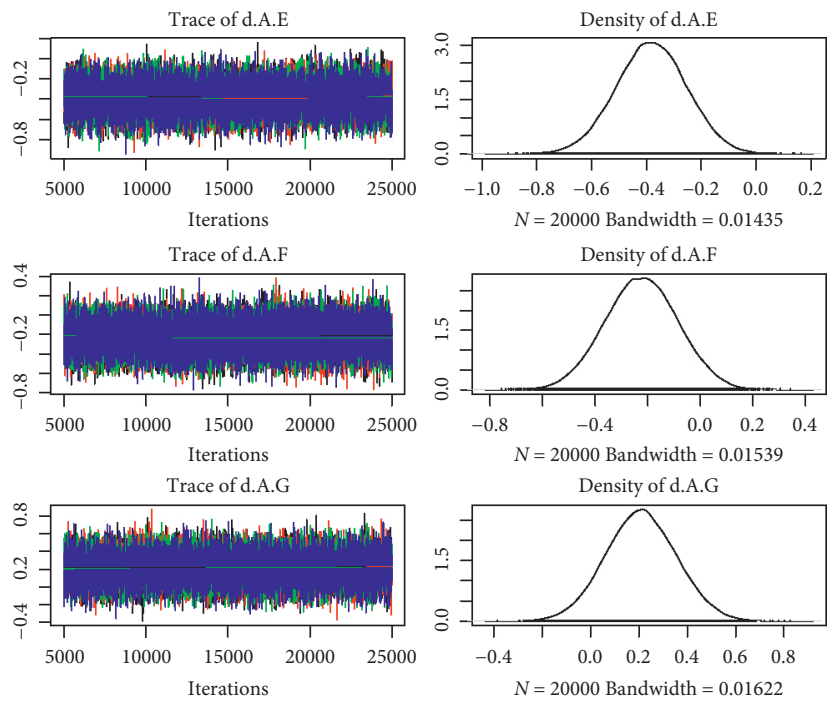

(c)

FiguRE 3: Brooks-Gelman-Rubin diagnostic plot and density plot for the safety of the comparison among different treatments of patients with normal renal function.

Gault formula: normal renal function (eGFR $>80 \mathrm{ml} / \mathrm{min}$ ), mild renal function (eGFR $>50$ and eGFR $<80 \mathrm{ml} / \mathrm{min}$ ), and moderate renal function $(e G F R>30$ and $e G F R<50)$.

2.5. Data Synthesis and Analysis. NMA was analyzed using R (version 3.5.1, R Foundation for Statistical Computing) with the packages gemtc recalling JAGS (version 4.3.0) based on 20,000 iterations for each four MCMC chains with a burn-in period of the initial 5,000 iterations. NetMetaXL (version 1.6.1) and winBUGS (version 1.4.3) were used to obtain the cumulative ranking curve (SUCRA) of each drug. The odds ratio (OR) and $95 \%$ confidence interval (CI) were used to analyze the efficacy and safety of the NOACs. As the efficacy and safety all were defined as bad events, OR over 1.0 and CI not containing 1.0 meant the bad effect relatively [17].
The simple ranking probability from $\mathrm{R}$ and packages gemtc could not offer a better suggestion for the patient to choose the proper one; as a consequence, here we calculated the SUCRA of each drug with the help of NetMetaXL and winBUGS. Larger SUCRA often meant the large tendency to achieve a better ending [18]. Although the random-effect model was more fit for our NMA than a fixed-model, it may create the poor estimates for only four RCTs included. As a result, we analyzed with both random and fixed-effect model in a Bayesian framework. The totresdev and deviance information criterion (DIC) and the residual deviance $(\mathrm{pD})$ of the two models were calculated to identify the difference relatively [19]. Considering that the data of our NMA was sparse, we used informative prior to identify the heterogeneity, as was reviewed in previous article [20]. Trace plots, the Brooks-Gelman-Rubin diagnostic, and PSFR were used 

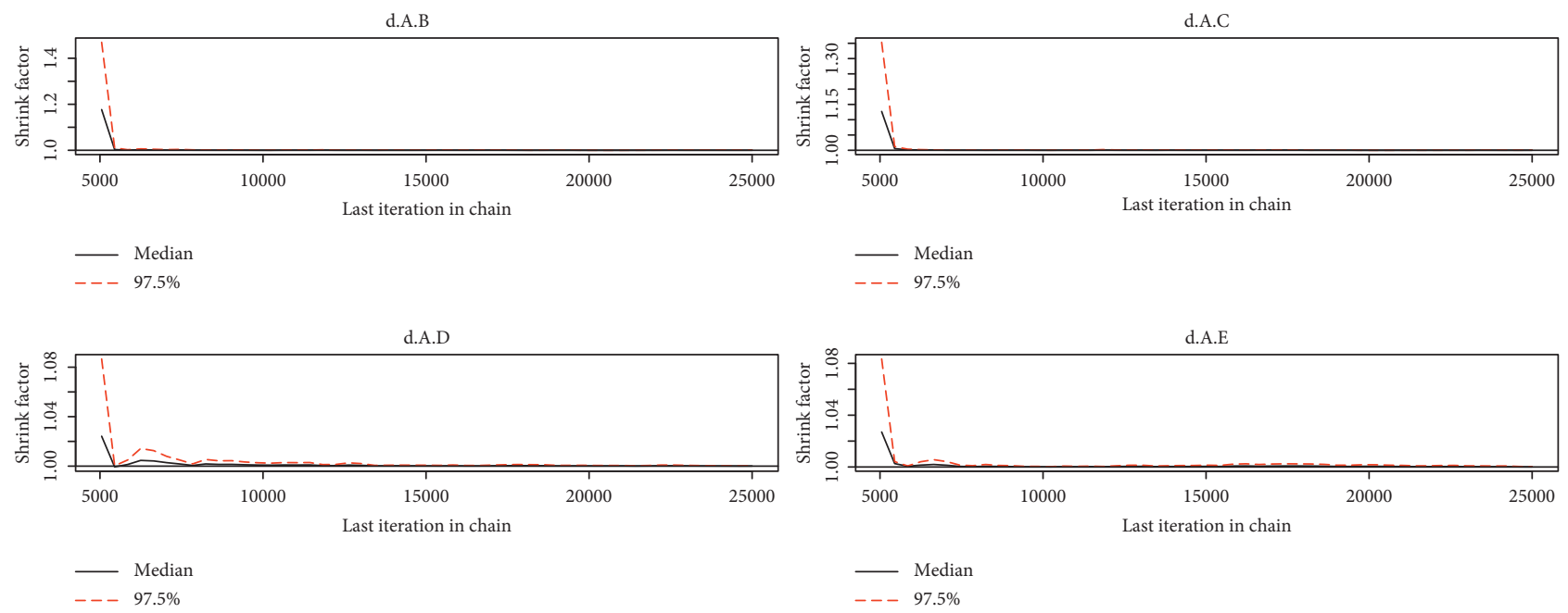

d.A.F
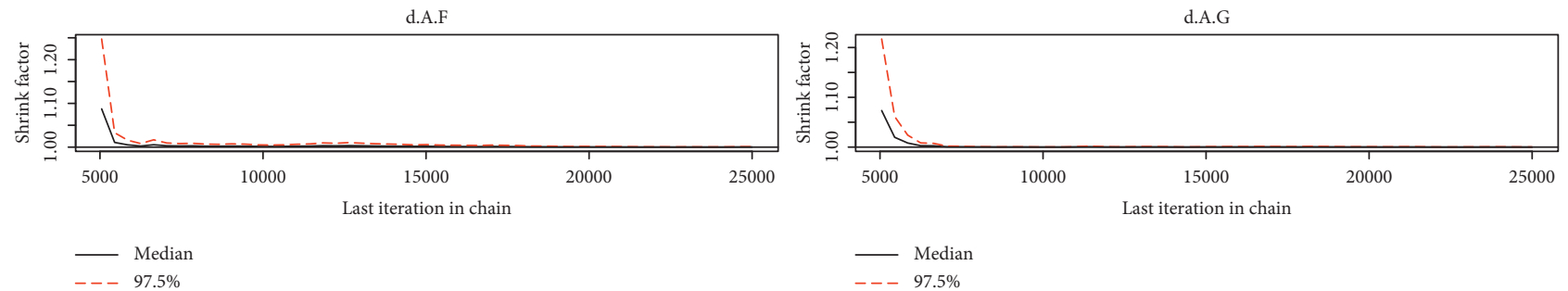

(a)
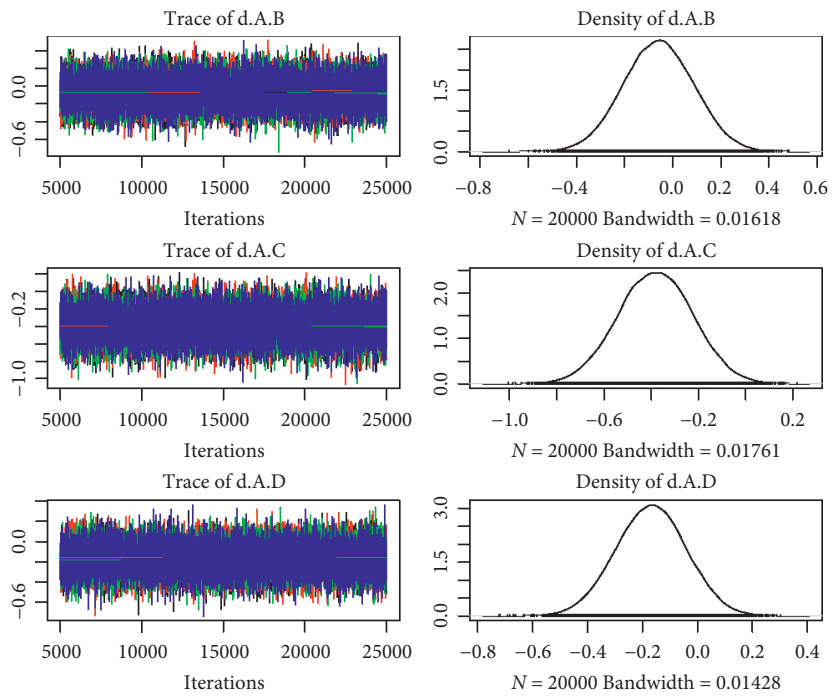

(b)

FIGURE 4: Continued. 

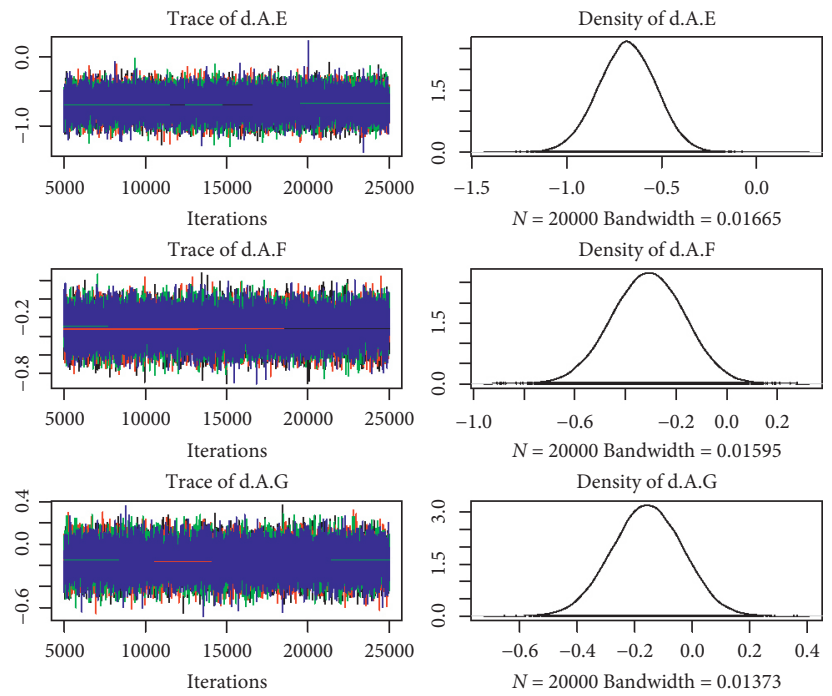

(c)

Figure 4: Brooks-Gelman-Rubin diagnostic plot and density plot for the efficacy of the comparison among different treatments of patients with mild renal function.
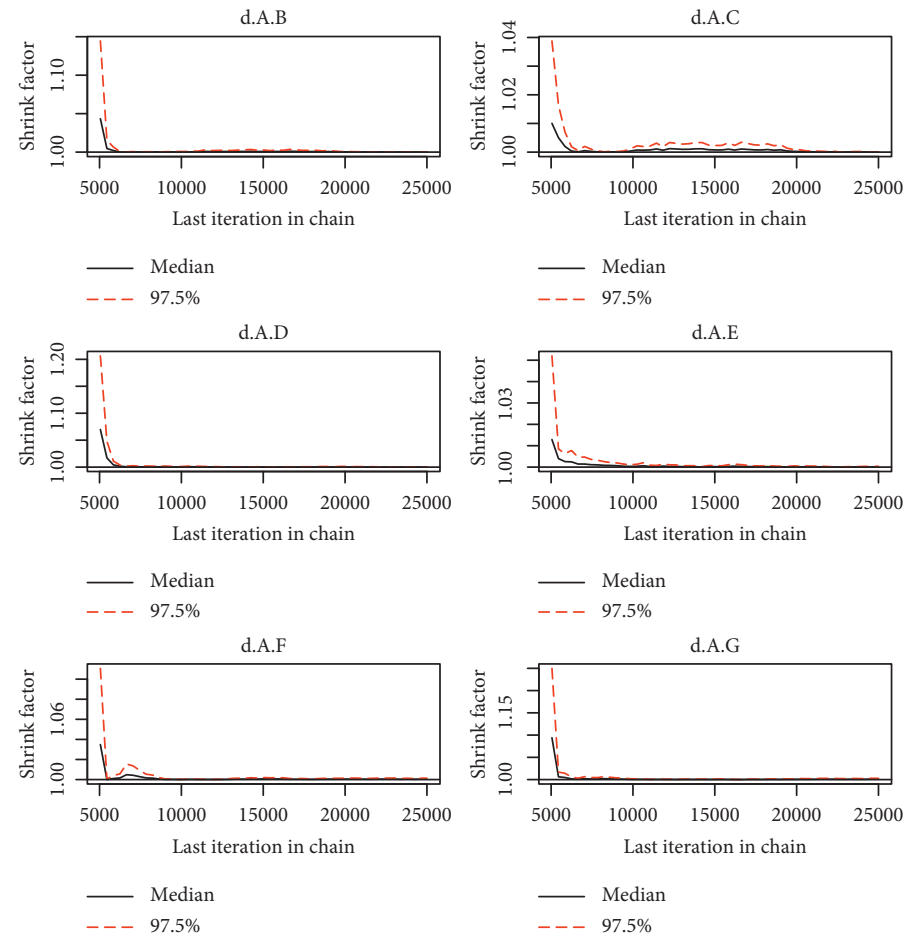

(a)

FIGURE 5: Continued. 

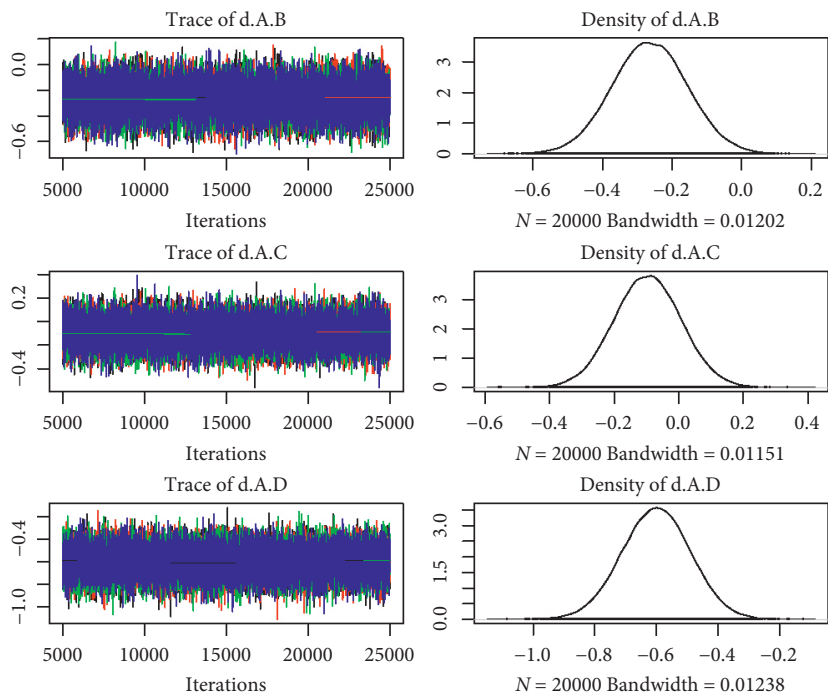

(b)
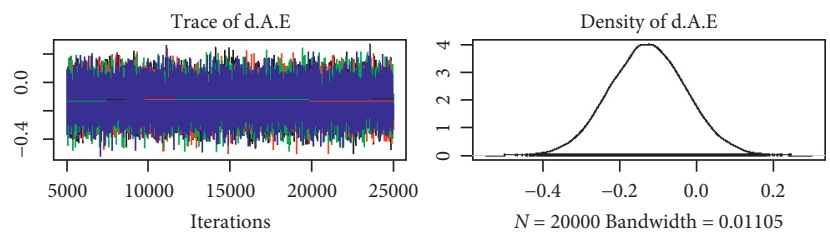

Trace of d.A.F
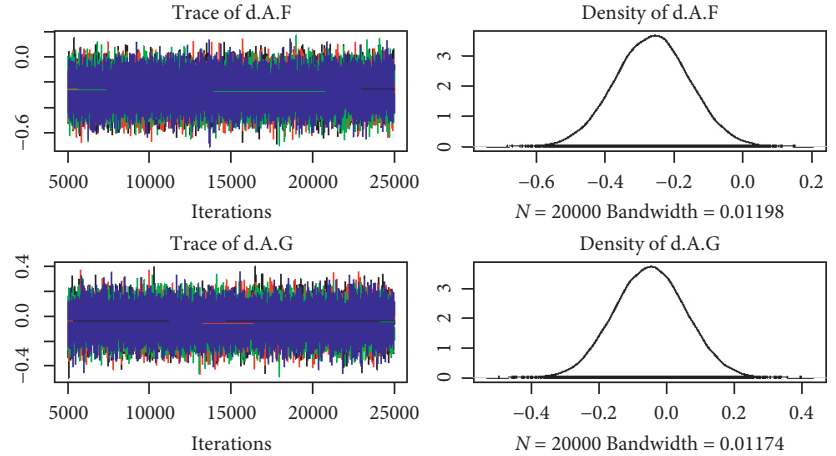

(c)

FiguRE 5: Brooks-Gelman-Rubin diagnostic plot and density plot for the safety of the comparison among different treatments of patients with mild renal function.

to ensure the convergence [21]. Taking the network plot without any loops into consideration, we found it impossible to make the evaluation of the consistency of direct and indirect comparisons.

\section{Results}

As is shown in Figure 1, 15640 included records were identified from EMBASE $(n=7554)$, PubMed $(n=663)$, Web of Science $(n=6348)$, and Cochrane library $(n=1075)$, and 3950 duplicates were removed. Subsequently, 11482 records were removed for not meeting the inclusion criteria and 208 records were assessed based on full-text screening. Finally, nine studies were included in our NMA identifying four phase III RCTs (RE-LY [6, 22, 23], ROCKET-AF [7], ARISTOTLE [8, 24], and ENGAGE AF-TIMI 48 [9, 25, 26]), which enrolled 71681 patients, and all the trials of low bias (Table 2). Data of the incidence of clinical outcomes was also obtained from U.S.FOOD\&DRUG. The baseline characteristics of the four RCTs are shown in Table 3. In general, there seemed a little difference with respect to the age and the percentage of the women for patients participating in the trials. The four RCTs all showed high rates of paroxysmal AF in comparison to persistent or permanent AF. Patients of ROCKET-AF had a higher rate of previous VKA use, previous stroke, heart failure, and diabetes mellitus than the other trails. Besides that, patients of ROCKET-AF seemed to have a higher risk as the comparison of mean CHADS2 score between the four RCTs. Mean follow-up of the trials ranged from 1.8 to 2.8 years.

3.1. Bayesian Network Meta-Analysis. For the convergence of our NMA, the Brooks-Gelman-Rubin diagnostic plot and density plot were obtained (Figures $2-7$ ). We also calculated 

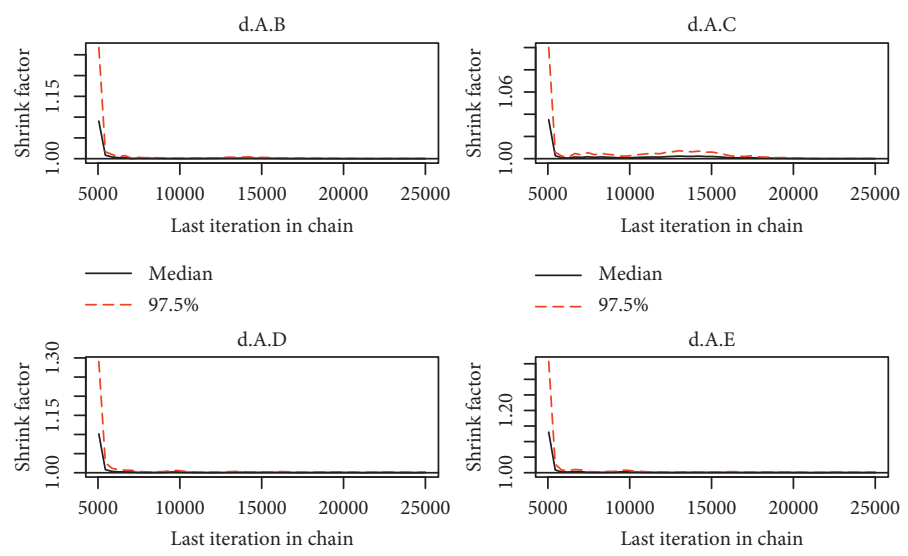

- Median

— Median

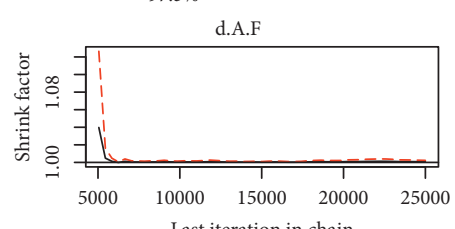

$-0.5 \%$

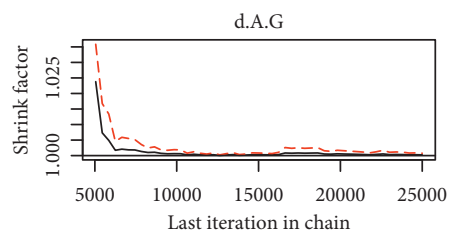

- Median

- - $97.5 \%$

— Median

- - $97.5 \%$

(a)
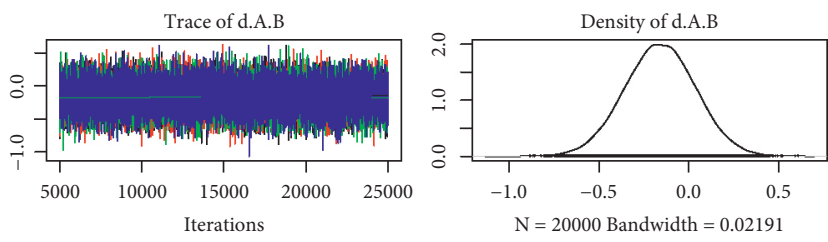

Trace of d.A.C Density of d.A.C
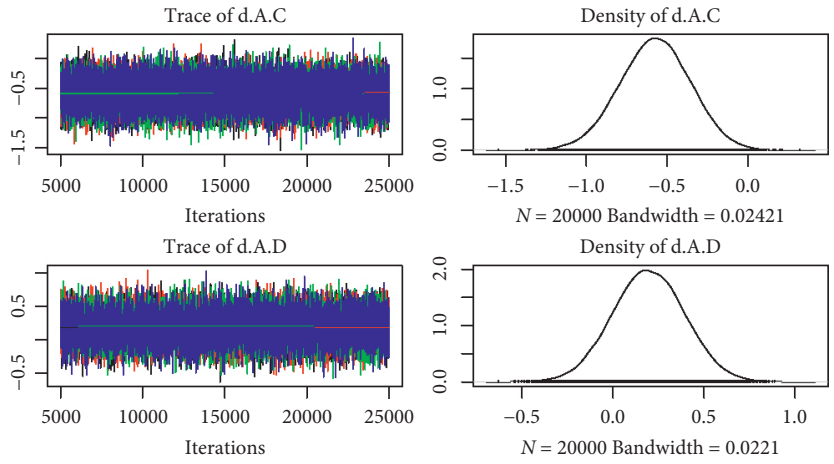

(b)

Figure 6: Continued. 

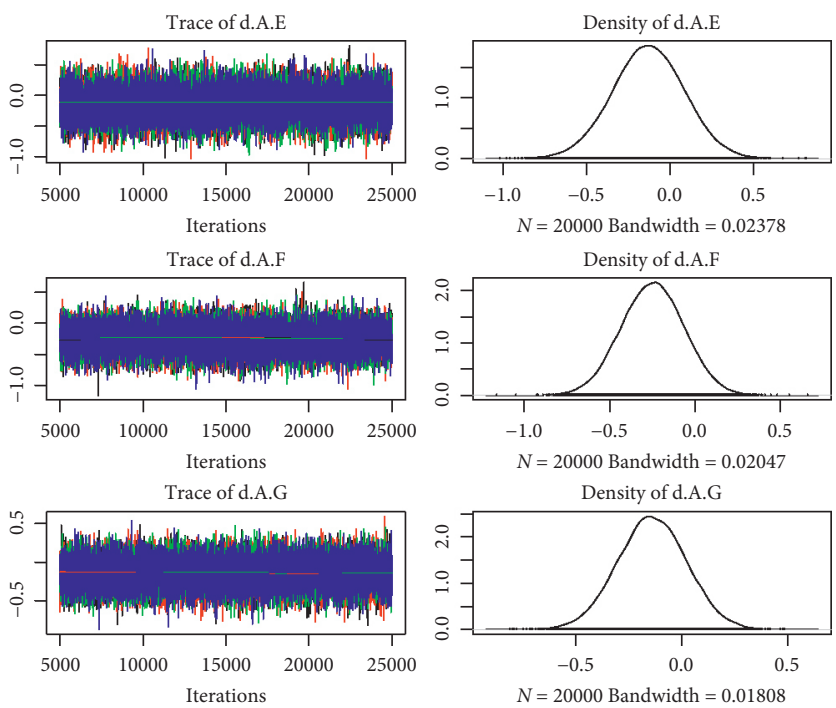

(c)

FIGURE 6: Brooks-Gelman-Rubin diagnostic plot and density plot for the efficacy of the comparison among different treatments of patients with moderate renal function.
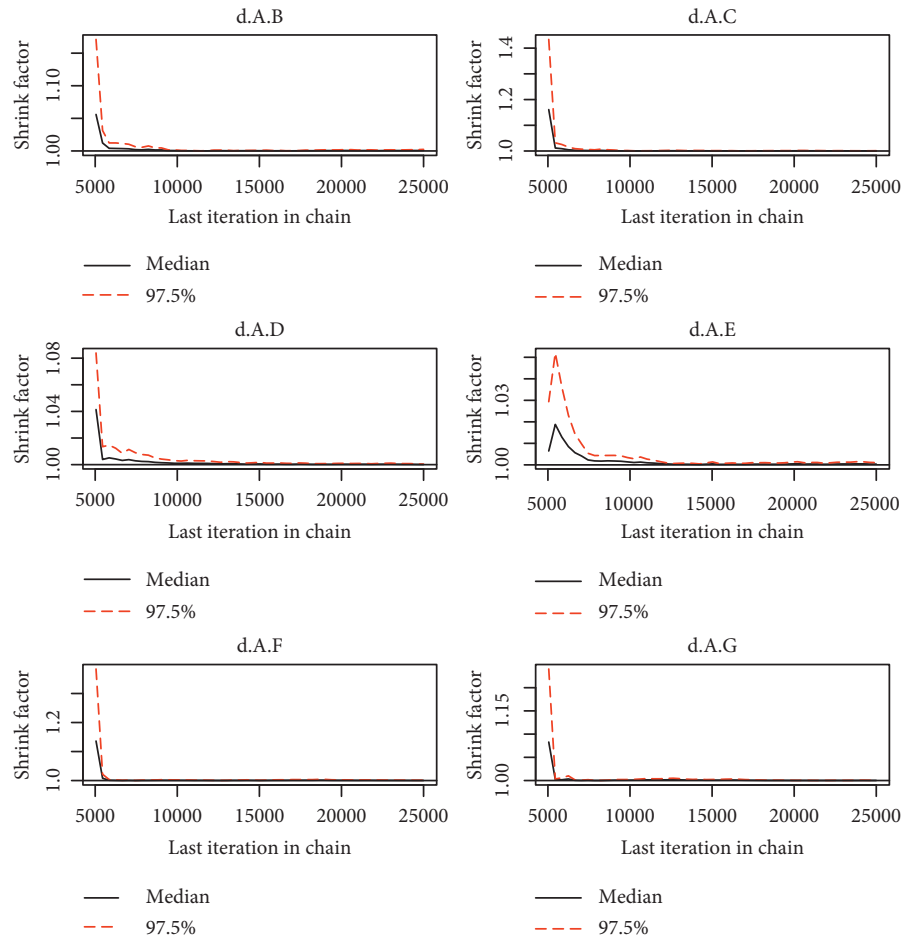

(a)

FIgURE 7: Continued. 

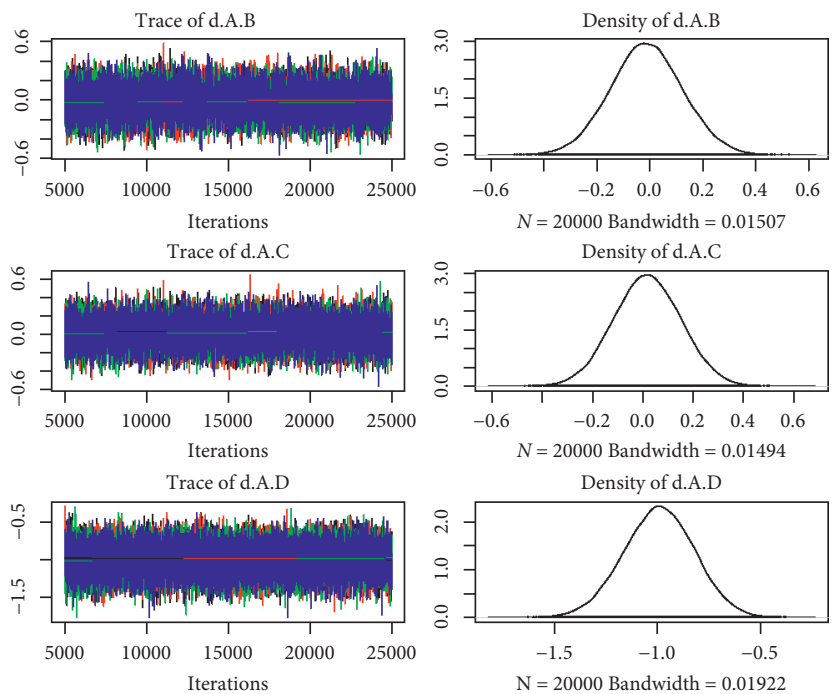

(b)
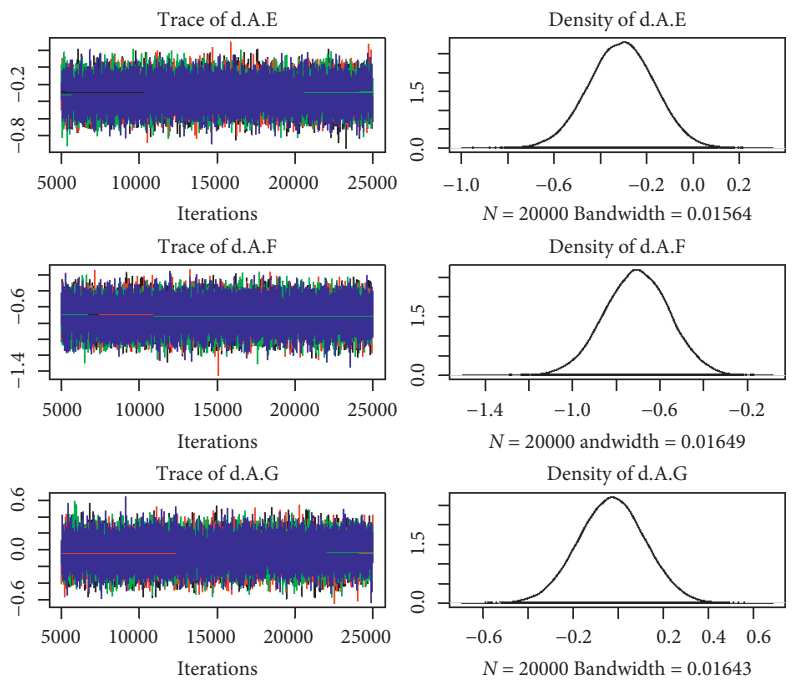

(c)

FiguRE 7: Brooks-Gelman-Rubin diagnostic plot and density plot for the safety of the comparison among different treatments of patients with moderate renal function.

PSRF for each analysis and each result of PSRF was close to 1. According to the plots and PSRF, the model fitted better.

The $\mathrm{pD}$ and DIC were all calculated for both fixed and random-effects models, with the result showing that $\mathrm{pD}$ of each model was closed 10.0 and DIC was 20.0 for all analysis based on renal function, meaning there was no difference between fixed and random-effects models.

3.2. Subgroups of Patients with Normal Renal Function. In comparison to edoxaban30, dabigatran 110 (OR: 0.52, 95\% CI: 0.29-0.93), dabigatran 150 (0.41, 0.22-0.76), apixaban $(0.54,0.33-0.89)$, rivaroxaban $(0.57,0.34-0.94)$, and even warfarin $(0.62,0.42-0.89)$ were associated with a reduction of stroke or systemic embolism, but not edoxaban60. Besides that, dabigatran $150(0.48,0.25-0.88)$ had lower rates relative to edoxaban 60 in terms of stroke or systemic embolism. No difference was detected between edoxaban60 and edoxaban30 (Figure 8). $(\tau 2=0.13$, 95\% CI 0.04-0.43) Dabigatran 150 ranked as the most effective drug (SUCRA 0.90), followed by dabigatran 110 (SUCRA 0.68), apixaban (SUCRA 0.66), and rivaroxaban (SUCRA 0.59) (Figure 9).

In contrast, the risk of major bleeding for patients treated with edoxaban30 was lower than dabigatran150 (0.51, $0.33-0.77)$, edoxaban60 $(0.63,0.46-0.85)$, apixaban $(0.54$, $0.36-0.80)$, and rivaroxaban $(0.35,0.23-0.52)$. In addition, dabigatran 110 was associated with decreased risk of major bleeding compared to dabigatran $150(0.71,0.5-1.0)$ and rivaroxaban $(0.49,0.31-0.75)$. Besides, edoxaban60 (0.55, $0.38-0.81)$ and apixaban $(0.65,0.43-0.96)$ reduced the risk of major bleeding contrast to rivaroxaban. But the difference between dabigatran 110 and edoxaban 30 was not significant. In comparison to warfarin, dabigatran $110(0.6,0.43-0.83)$, 

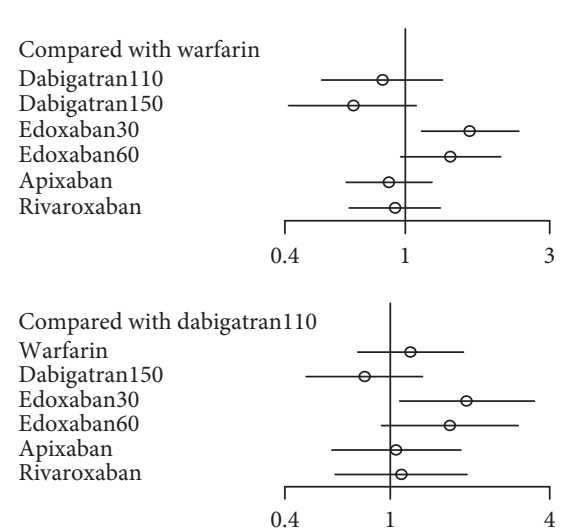

Compared with dabigatran 150

Warfarin

Dabigatran 110

Edoxaban30

Edoxaban60

Apixaban

Rivaroxaban

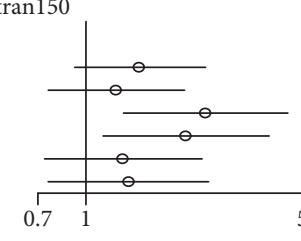

Compared with edoxaban 30

Warfarin

Dabigatran 110

Dabigatran 150

Edoxaban60

Apixaban

Rivaroxaban

Compared with edoxaban60

Warfarin

Dabigatran 110

Dabigatran 150

Edoxaban30

Apixaban

Rivaroxaban

Compared with apixaban Warfarin

Dabigatran 110

Dabigatran 150

Edoxaban30

Edoxaban60

Rivaroxaban

Compared with rivaroxaban

Warfarin

Dabigatran110

Dabigatran150

Edoxaban 30

Edoxaban60

Apixaban
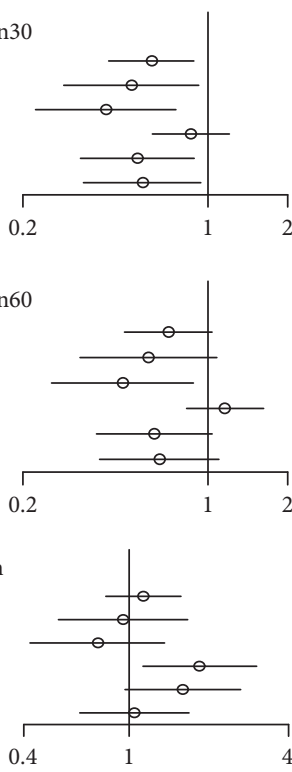

Odds ratio (95\% CrI)

$0.84(0.53,1.3)$

$0.67(0.41,1.1)$

$1.6(1.1,2.4)$

$1.4(0.96,2.1)$

$0.88(0.63,1.2)$

$0.93(0.66,1.3)$

Odds ratio (95\% CrI)

$1.2(0.75,1.9)$

$0.80(0.48,1.3)$

$1.9(1.1,3.5)$

$1.9(1.1,3.5)$
$1.7(0.93,3.1)$

$1.0(0.59,1.9)$

$1.1(0.62,2)$

Odds ratio (95\% CrI)

$1.5(0.9,2.5)$

$1.3(0.76,2.1)$

$2.4(1.3,4.5)$

$2.4(1.3,4.5)$

$2.1(1.1,3.9)$

$1.3(0.73,2.4)$
$1.4(0.76,2.5)$

Odds ratio (95\% CrI)

$0.62(0.42,0.89)$

$0.52(0.29,0.93)$

$0.41(0.22,0.76)$

$0.41(0.22,0.76)$
$0.86(0.62,1.2)$

$0.54(0.33,0.89)$

$0.57(0.34,0.94)$

Odds ratio $(95 \% \mathrm{CrI})$

$0.71(0.49,1.0)$

$0.60(0.33,1.1)$

$0.48(0.25,0.88)$

$1.2(0.83,1.6)$

$0.63(0.38,1.0)$

$0.66(0.39,1.1)$

Odds ratio (95\% CrI)

$1.1(0.82,1.6)$

$0.95(0.54,1.7)$

$0.76(0.42,1.4)$

$1.8(1.1,3.0)$

$1.6(0.97,2.6)$

$1.6(0.97,2.6)$
$1.0(0.66,1.7)$

Odds ratio $(95 \% \mathrm{CrI})$

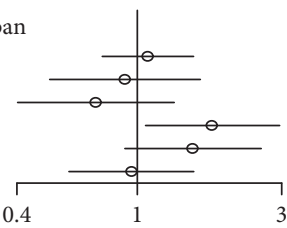

$1.1(0.76,1.5)$

$0.91(0.51,1.6)$

$0.73(0.40,1.3)$

$1.8(1.1,2.9)$

$1.5(0.91,2.5)$
$0.96(0.59,1.5)$

FIGURE 8: Ranking plots for the efficacy of the comparison among different treatments of patients with normal renal function.

edoxaban $30(0.43,0.32-0.57)$, and edoxaban60 (0.68, $0.53-0.88)$ were associated with relative risk reduction (Figure 10) $(\tau 2=0.13,0.04-0.44)$.

There was high probability that edoxaban30 (SUCRA 0.99) ranked first for the preventing the major bleeding, in comparison to dabigatran110 (SUCRA 0.78) and edoxaban60 (SUCRA 0.66) (Figure 11).
3.3. Subgroup of Patients with Mild Renal Function. Dabigatran110 (1.9, 1.2-2.8), edoxaban30 (1.7, 1.2-2.3), and rivaroxaban $(1.7,1.2-2.5)$ took higher risk than edoxaban 60 with respect to stroke or systemic embolism. In addition, dabigatran 150 had lower risk than dabigatran110 (0.73, $0.53-0.99)$. In comparison to warfarin, dabigatran $150(0.68$, $0.50-0.93)$, edoxaban $60(0.51,0.380 .68)$, and apixaban $(0.73$, 


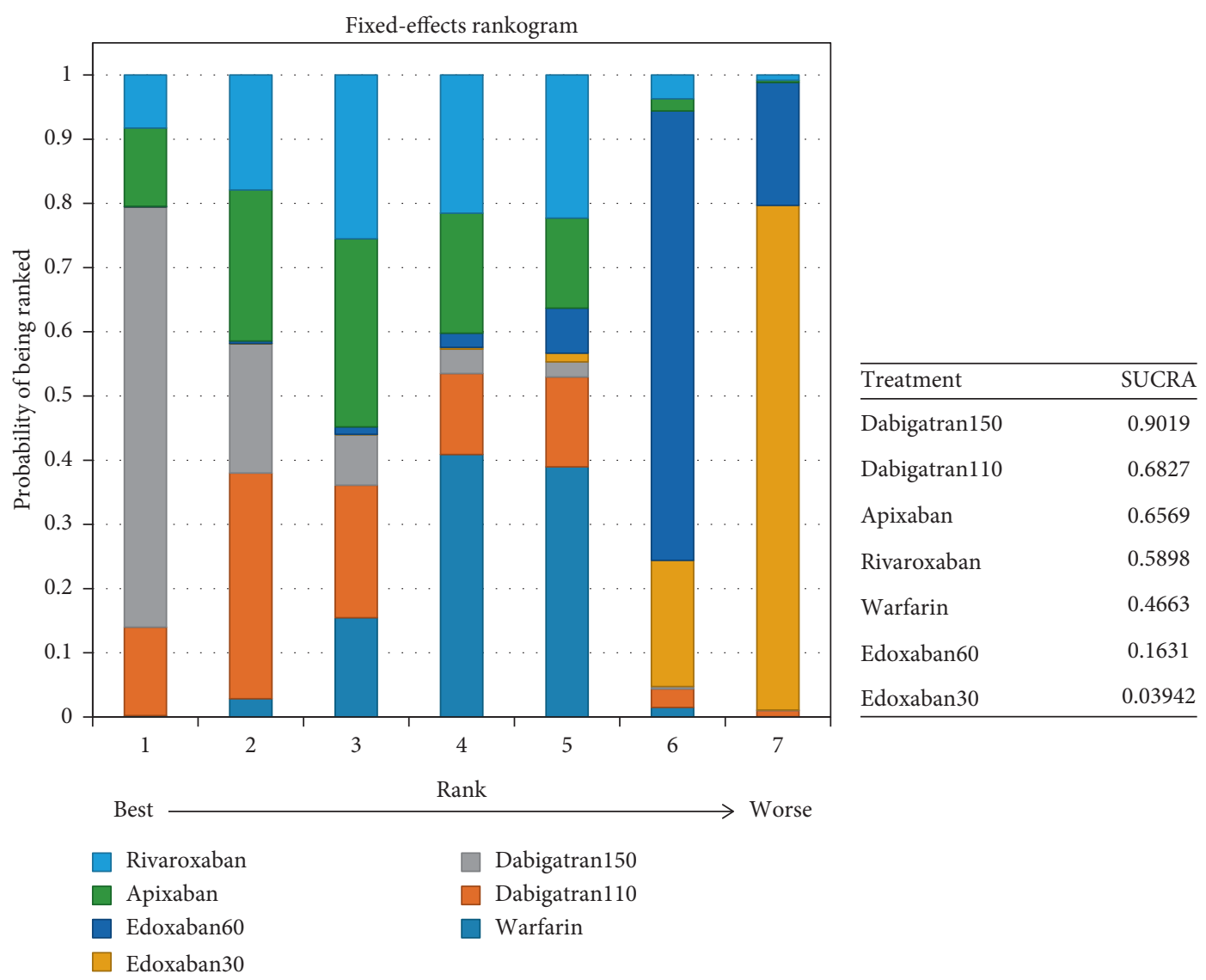

FiguRE 9: Ranking plots for the efficacy of the comparison among different treatments of patients with normal renal function (ranking indicates the probability to be the best treatment, the second best, the third best, and so on).

0.55-0.97) were more effective. There was no evidence to prove the difference among the NOACs left (Figure 12) $(\tau 2=0.13,0.04-0.44)$.

With respect to the most effective drug for preventing stroke or systemic embolism, edoxaban60 ranked first (SUCRA 0.98), followed by dabigatran150 (SUCRA 0.74) and apixaban (SUCRA 0.64) (Figure 13).

All the drugs had an increased rates of major bleeding in comparison to edoxaban30, including warfarin (1.8, 1.5-2.3), dabigatran110 (1.4, 1.0-1.9), dabigatran 150 (1.7, 1.2-2.3), edoxaban60 (1.6, 1.3-2.0), apixaban (1.4, 1.0-1.9), and rivaroxaban $(1.7,1.3-2.4)$. Compared to warfarin, dabiga$\operatorname{tran} 110(0.77,0.62-0.95)$ and apixaban $(0.77,0.62-0.95)$ took lower risk of major bleeding. In contrast, the difference among other interventions was not significant (Figure 14) $(\tau 2=0.13,0.04-0.42)$.

Possibility of ranking first for the safest drug was edoxaban30 (SUCRA 0.99), followed by dabigatran 110 (SUCRA 0.70) and apixaban (SUCRA 0.69) (Figure 15).

\subsection{Subgroup of Patients with Moderate Renal Function.} In patients with moderate renal impairment, dabiga$\operatorname{tran} 150$ reduced the rates of stroke or systemic embolism compared to warfarin $(0.56,0.36-0.86)$ and edoxaban 30 $(0.46,0.26-0.82)$. There was no difference detected among other interventions (Figure 16) $(\tau 2=0.13$,
0.04-0.43). Dabigatran150 (SUCRA 0.95) ranked as the most effective drug compared to apixaban (SUCRA 0.66). Dabigatran110 (SUCRA 0.53), rivaroxaban (SUCRA 0.51), and edoxaban60 (SUCRA 0.50) had the similar probability of ranking third (Figure 17). Dabigatran 110 $(2.7,1.7-4.1)$, dabigatran 150 (2.7, 1.8-4.2), edoxaban60 $(2.0,1.4-2.8)$, and rivaroxaban $(2.6,1.7-4.1)$ were more dangerous for major bleeding than edxaban30. Besides, dabigatran 110 (2.0, 1.3-3), dabigatran150 (2.1, 1.4-3.1), and rivaroxaban $(2.0,1.3-3)$ also increased the risk of major bleeding in contrast to apixaban. Compared to warfarin, edoxaban30 (0.37, 0.26-0.52), edoxaban60 $(0.74,0.56-0.97)$, and apixaban $(0.49,0.37-0.66)$ were associated with reduced risks of major bleeding (Figure 18) $(\tau 2=0.13,0.04-0.43)$.

Probability of being the safest drug for preventing major bleeding was edoxaban30 (SUCRA 0.98), in comparison to apixaban (SUCRA 0.85) and edoxaban60 (SUCRA 0.64) (Figure 19).

\section{Discussion}

According to the recent studies published, renal function was an independent risk for stroke. In spite of numerous studies evaluating the effect of NOACs for preventing stroke or systemic embolism, few articles placed emphasis on the 


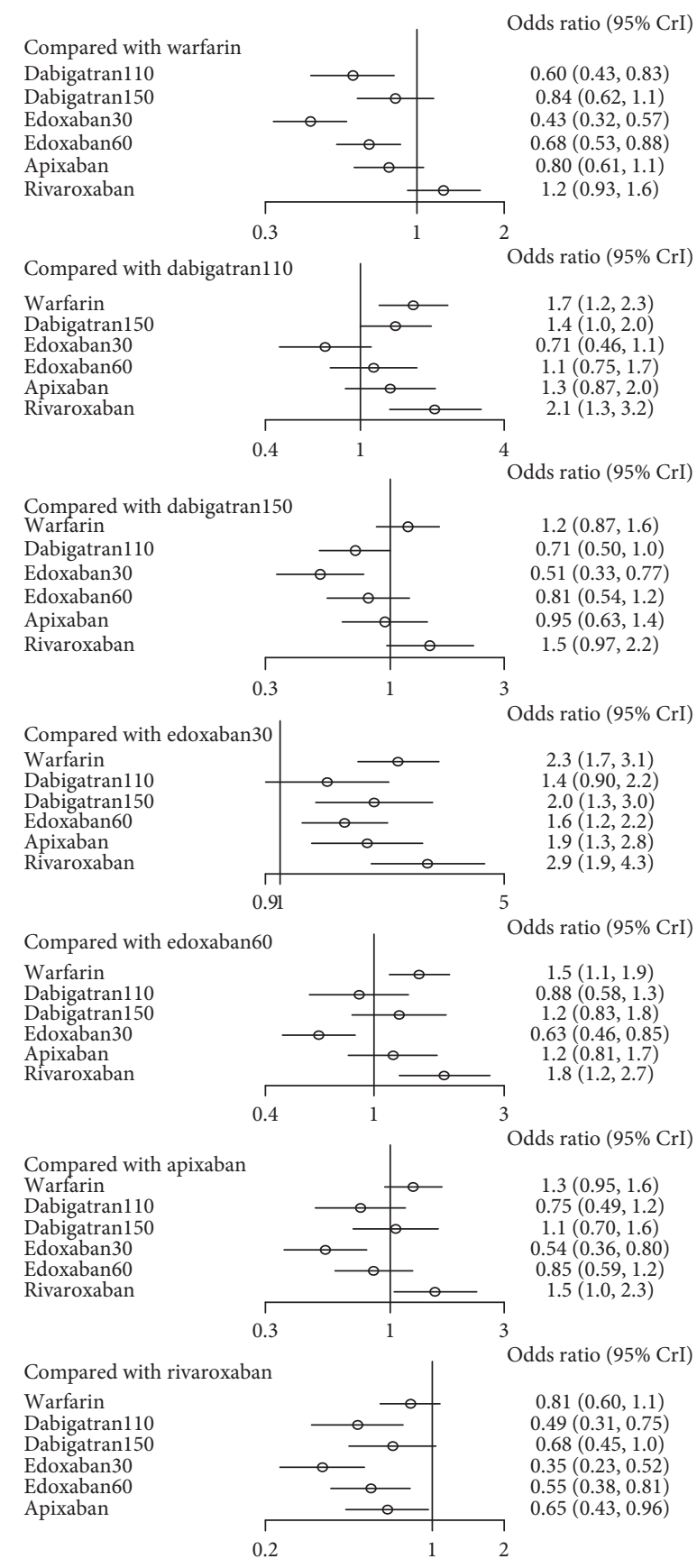

FIGURE 10: Forest plot for the safety of the comparison among different treatments of patients with normal renal function.

effects of NOACs for preventing stroke or systemic embolism and major bleeding in patients with different degrees of renal function, especially for head-to-head comparisons. With the aim to offer the better choice for patients with different levels of renal function, we identified 4 RCTs comparing the NOACs with respect to preventing stroke or systemic embolism and major bleeding in patients with different renal impairment in the NMA.

4.1. For Patients with Normal Renal Function. In patents with normal renal function, dabigatran 150 (SUCRA 0.90) was the most effective drug for preventing stroke or systemic embolism in comparison to the edoxaban30 and edoxaban60, and dabigatran 110 (SUCRA 0.68) was the second with effective prevention for stroke or systemic embolism, whereas edoxaban30 ranked as the least effective drug. When it referred to the safest drug, edoxaban30 (SUCRA 0.99) was associated with the great reduction of major bleeding compared to the other NOACs despite the least effective drug (SUCRA 0.04). In comparison, dabigatran110 (SUCRA 0.77) ranked second for preventing major bleeding and no significant difference was detected between edoxaban30 and dabigatran110. Despite dabigatran150 ranking as the most 


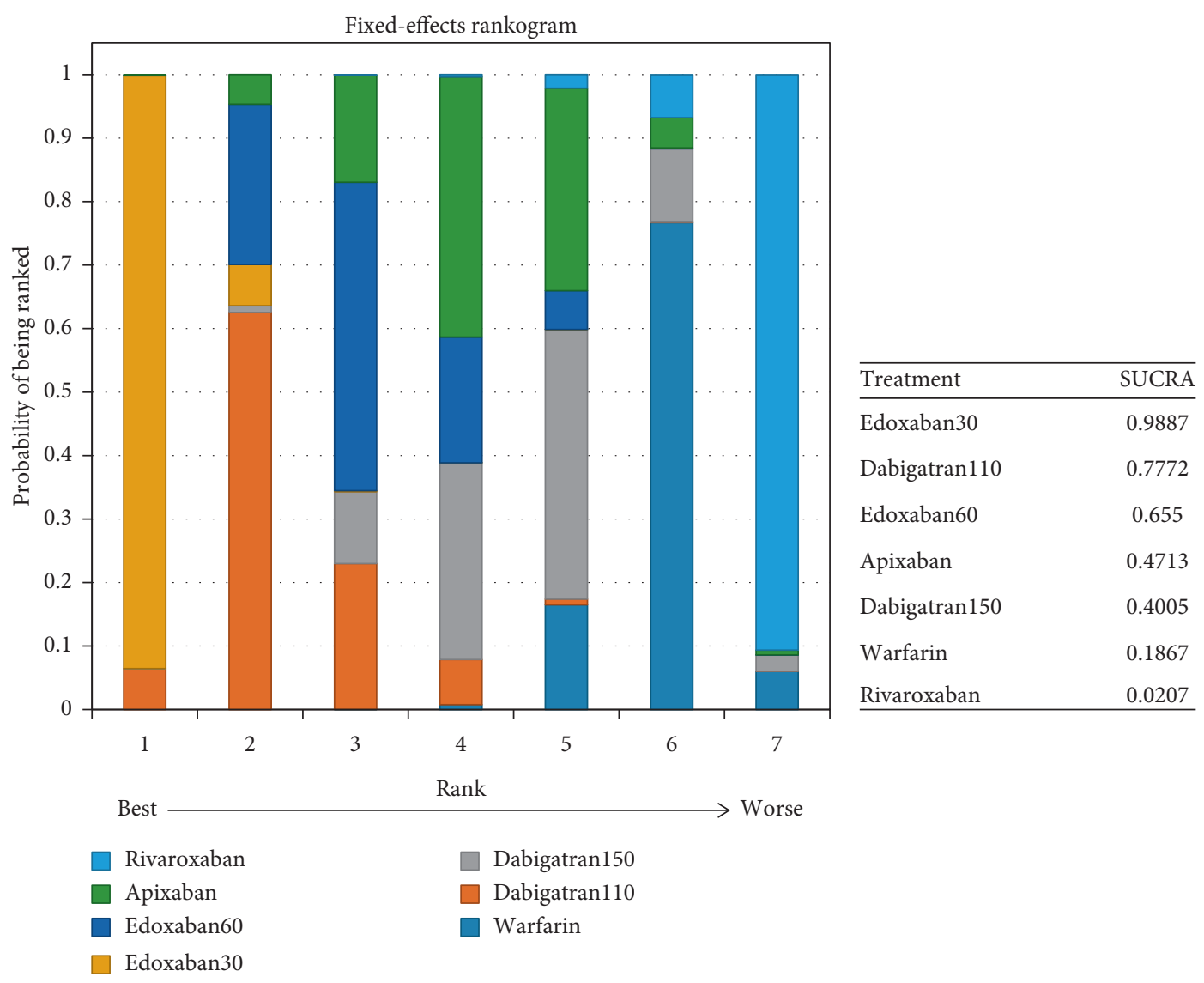

FIgURE 11: Ranking plots for the safety of the comparison among different treatments of patients with normal renal function.

effective drug for preventing stroke or systemic embolism, the safety of such drug did not rank better (SUCRA 0.40). In comparison, dabigatran110 ranked second for preventing both stroke or systemic embolism (SUCRA 0.68) and major bleeding (SUCRA 0.77), meaning that dabigatran 110 would be a better choice for patients with normal renal function.

A recent network meta-analysis published in 2018 compared different NOACs for their risk of $\mathrm{ICH}$ in patients with AF or venous thromboembolism (VTE), which drew a conclusion that dabigatran110 (SUCRA 0.83) ranked as the safest drug, but the NMA did not include the low dose edoxaban [27]. Another Bayesian meta-analysis published in 2015 also concluded that edoxaban 30 was the safest drug with regard to preventing major bleeding, followed by dabigatran 110 in patients with AF [28], which was closely consistent with our findings in patents with normal or mild renal function.

4.2. For Patients with Mild Renal Function. In patients with mild renal impairment, edoxaban60 (SUCRA 0.98) ranked first for the most effective drug in comparison to dabigatran110, edoxaban30, and rivaroxaban, while no significant difference was detected when compared to dabigatran 150 or apixaban, with the former drug ranking second (SUCRA 0.74) and the latter ranking third (SUCRA 0.64). With respect to preventing major bleeding, edoxaban30 (SUCRA
0.99) ranked first as the most effective drug in comparison to the other NOACs. In comparison, dabigatran 110 ranked second (SUCRA 0.70) and apixaban ranked third (SUCRA 0.69). Although edoxaban60 offered the greatest preventing stroke or systemic embolism, the influence of preventing major bleeding would not make it a better choice for its ranking (SUCRA 0.35). Also, edoxaban30 (SUCRA 0.42) could not offer a better prevention for stroke or systemic embolism in spite of the safest drug, and the same to the safety of dabigatran150 (SUCRA 0.35) and the efficacy of dabigatran 110 (SUCRA 0.23). Compared to the other NOACs, apixaban would offer the better endings for both efficacy (SUCRA 0.64) and safety (SUCRA 0.69).

The article published by Katsanos et al. also gave the similar conclusion that apixaban would offer an optimal benefit in comparison to the other NOACs in terms of the efficacy and safety, which identified the four RCTs [29]. One meta-regression analysis also gave the findings that apixaban would offer a better safety profile for preventing major bleeding, as well as the effect of prevention stroke or systemic embolism in patients with mild renal impairment [30].

4.3. For Patients with Moderate Renal Function. For patients with moderate renal function, dabigatran 150 (SUCRA 0.95) ranked first as the most effective drug in comparison to edoxaban30, while no difference was detected among other NOACs. In comparison, apixaban (SUCRA 0.66) ranked 


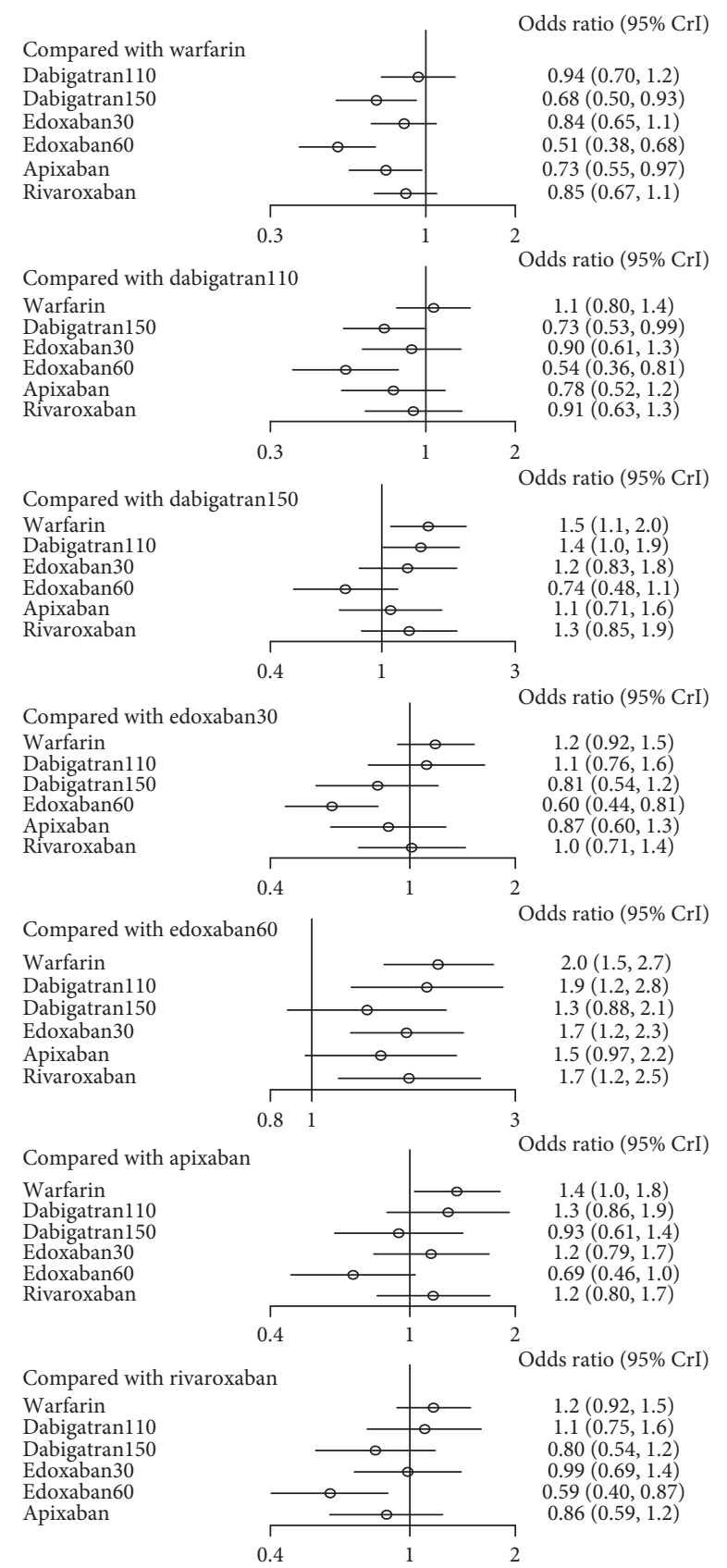

FIGURE 12: Forest plot for the efficacy of the comparison among different treatments of patients with mild renal function.

second, and dabigatran110 (SUCRA 0.53), rivaroxaban (SUCRA 0.51), and edoxaban60 (SUCRA 0.50) all could rank third. When it referred to preventing major bleeding, edoxaban30 (SUCRA 0.98) ranked as the safest drug in comparison to the other NOACs, but not apixaban, which ranked second (SUCRA 0.84), followed by edoxaban60 (SUCRA 0.64). Although dabigatran150 ranked first for preventing stroke or systemic embolism, it ranked as the least safe drug (SUCRA 0.21). And edoxaban (SUCRA 0.98) ranked as the least effective drug in spite of its best safety profile. In comparison, apixaban would be a better choice with respect to the efficacy (SUCRA 0.66) and safety
(SUCRA 0.85). In addition, edoxaban60 offered better results for its efficacy (SUCRA 0.50) and safety (SUCRA 0.64).

Our findings were consistent with one network metaanalysis that apixaban and edoxaban 60 would be a better choice in patients with moderate renal function [16] and one meta-regression analysis [30], which all include five RCTs.

Taking the characteristic of population into consideration, in comparison to the groups of patients treated with dabigatran150, edoxaban, apixaban, or rivaroxaban, patients associated with dabigatran 110 were younger and had lower CHADS2 score, less rates of heart failure, and previous VKA 


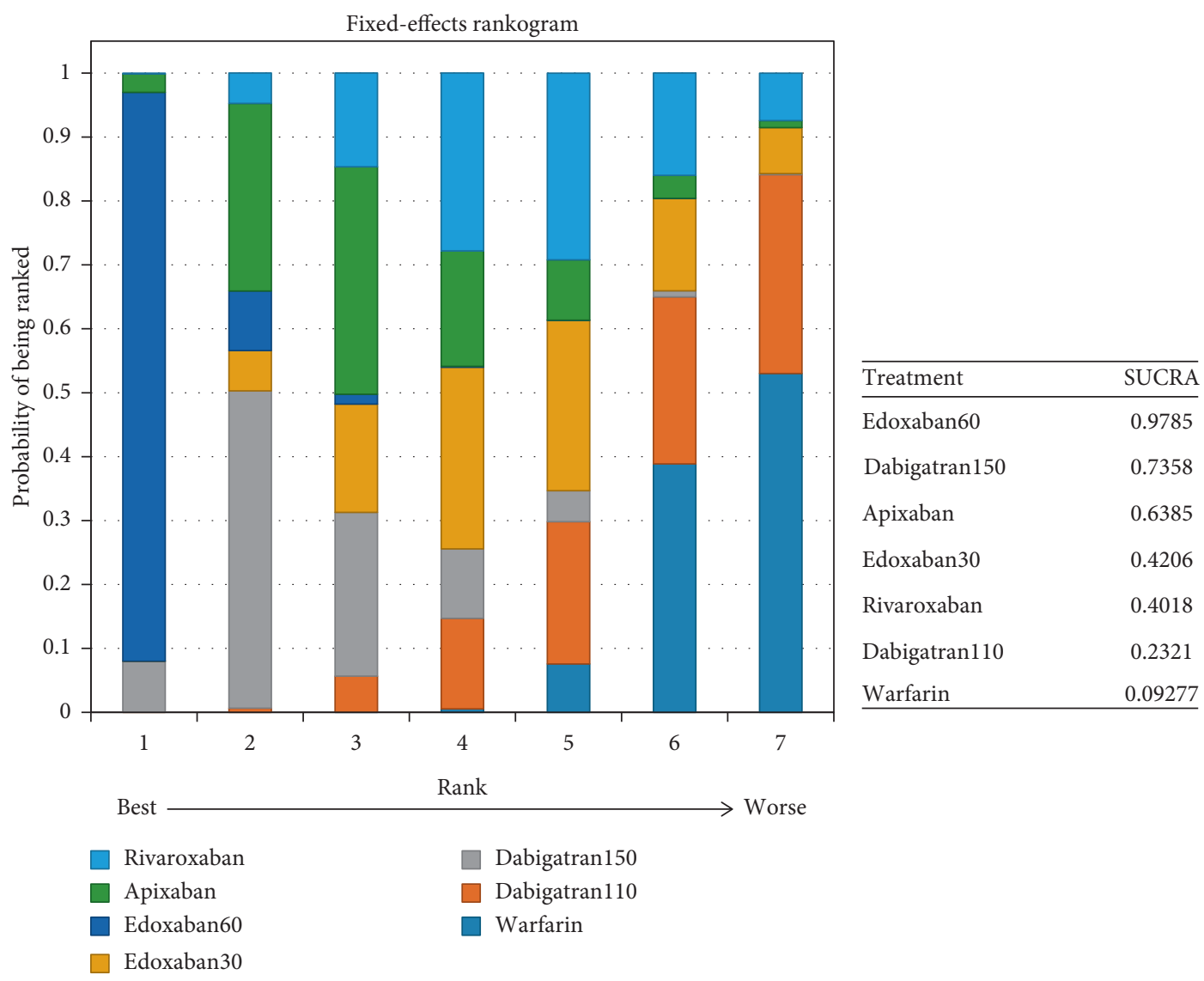

FIGURE 13: Ranking plots for the efficacy of the comparison among different treatments of patients with mild renal function. 


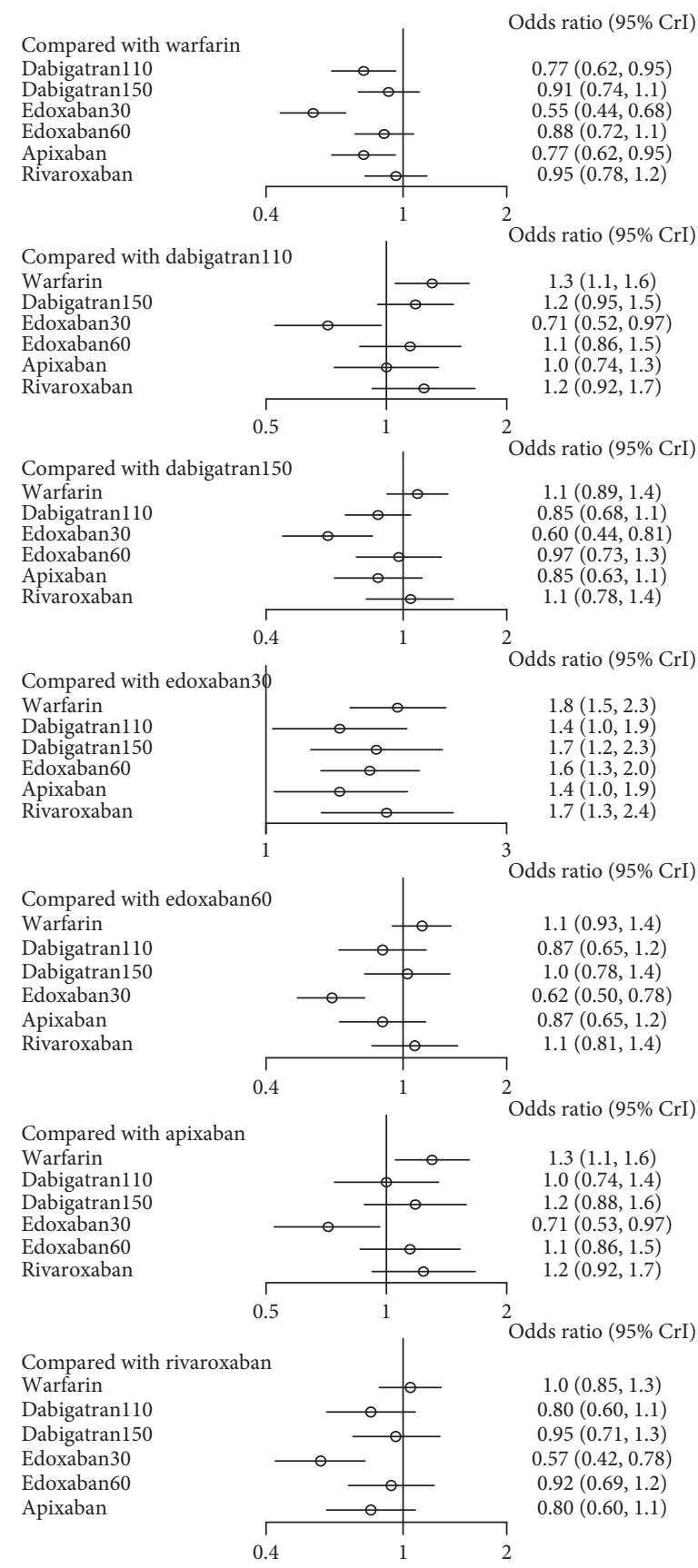

FIGURE 14: Forest plot for the safety of the comparison among different treatments of patients with mild renal function. 


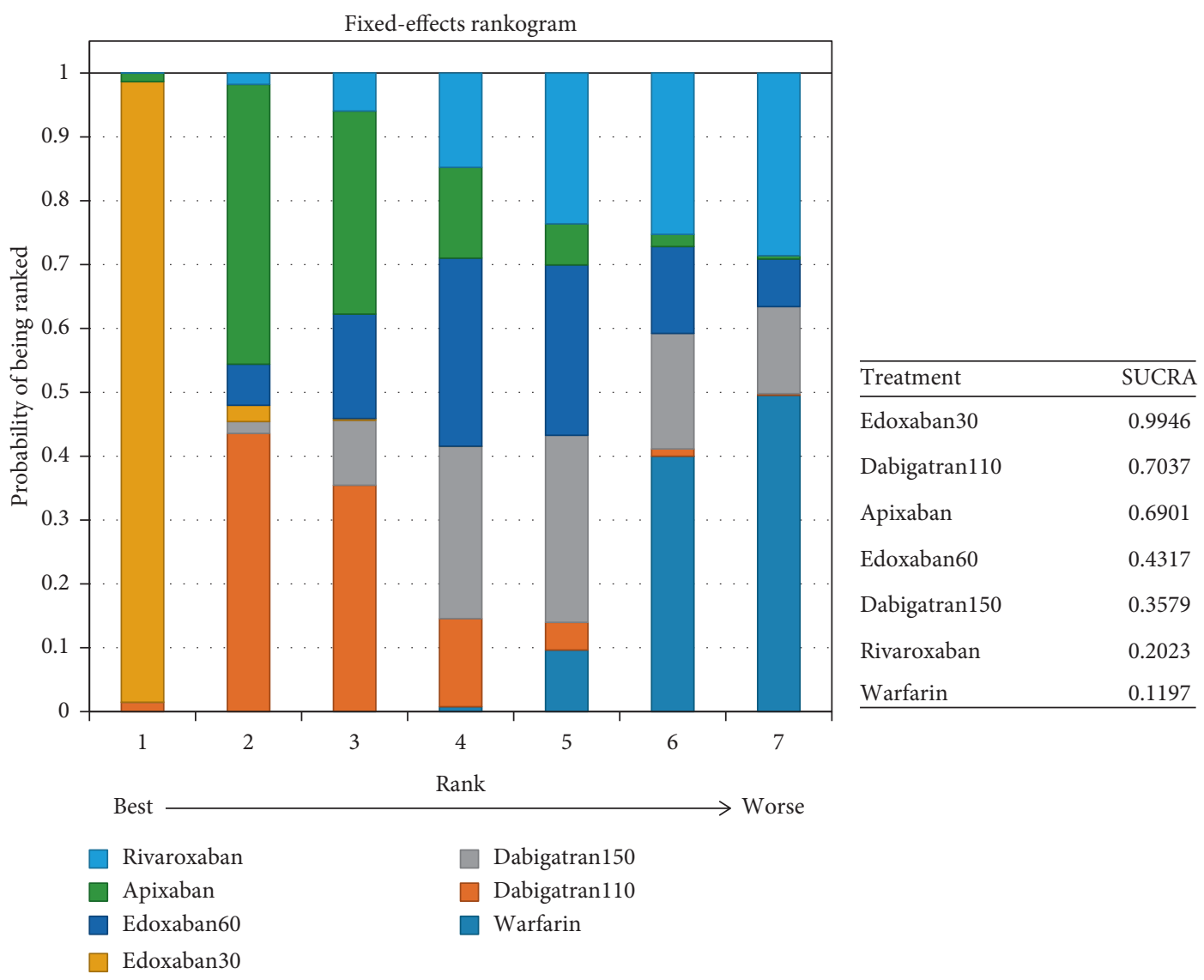

FIGURE 15: Ranking plots for the safety of the comparison among different treatments of patients with mild renal function. 

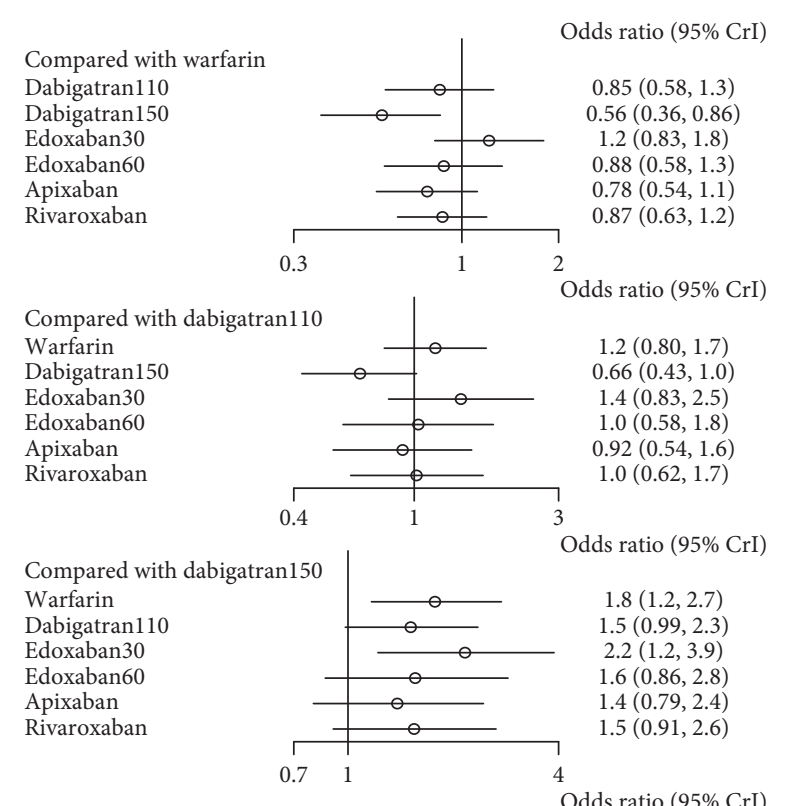

Compared with edoxaban30 $\quad$ Odds ratio (95\% CrI)
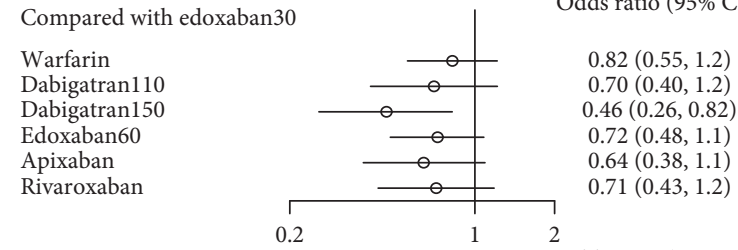

$1.8(1.2,2.7)$ $1.5(0.99,2.3)$

$2.2(1.2,3.9)$

$1.6(0.86,2.8)$

$1.4(0.79,2.4)$

$1.5(0.91,2.6)$

0.2

Compared with edoxaban 60

Warfarin

Dabigatran 110

Dabigatran 150

Edoxaban 30

Apixaban

Rivaroxaban

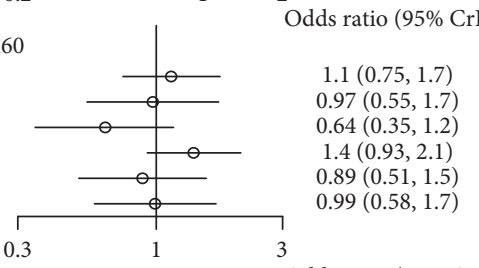

Compared with apixaban

Warfarin

Dabigatran 110

Dabigatran 150

Edoxaban 30

Edoxaban60

Rivaroxaban

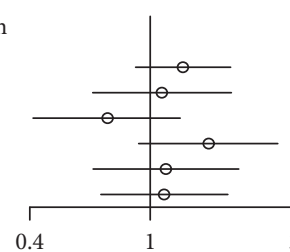

Odds ratio (95\% CrI)

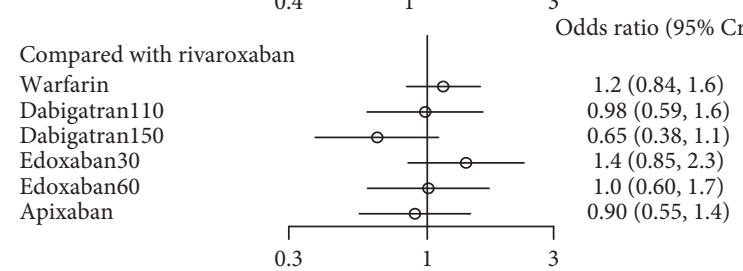

FiguRE 16: Forest plot for the efficacy of the comparison among different treatments of patients with moderate renal function. 


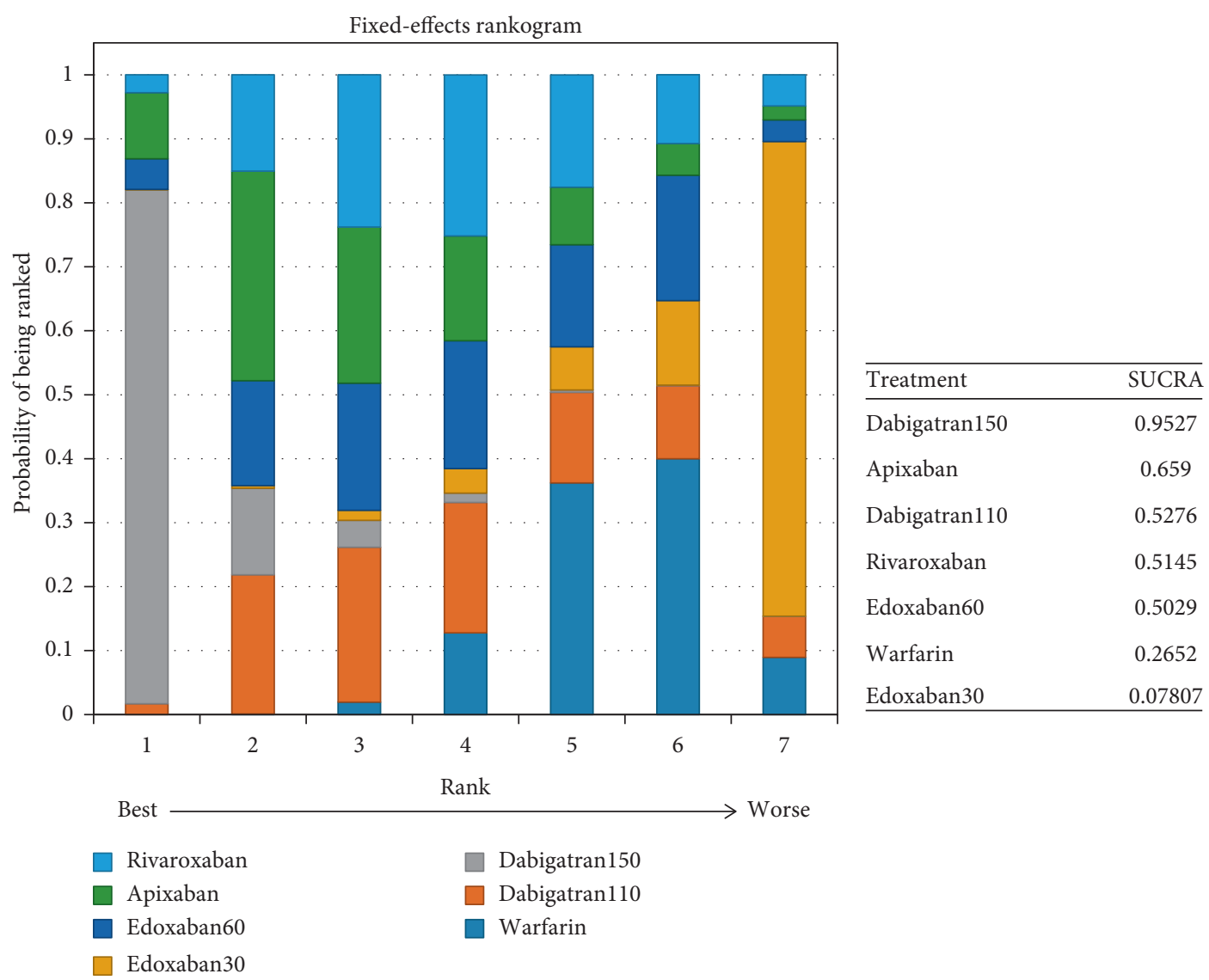

FIGURE 17: Ranking plots for the efficacy of the comparison among different treatments of patients with moderate renal function. 


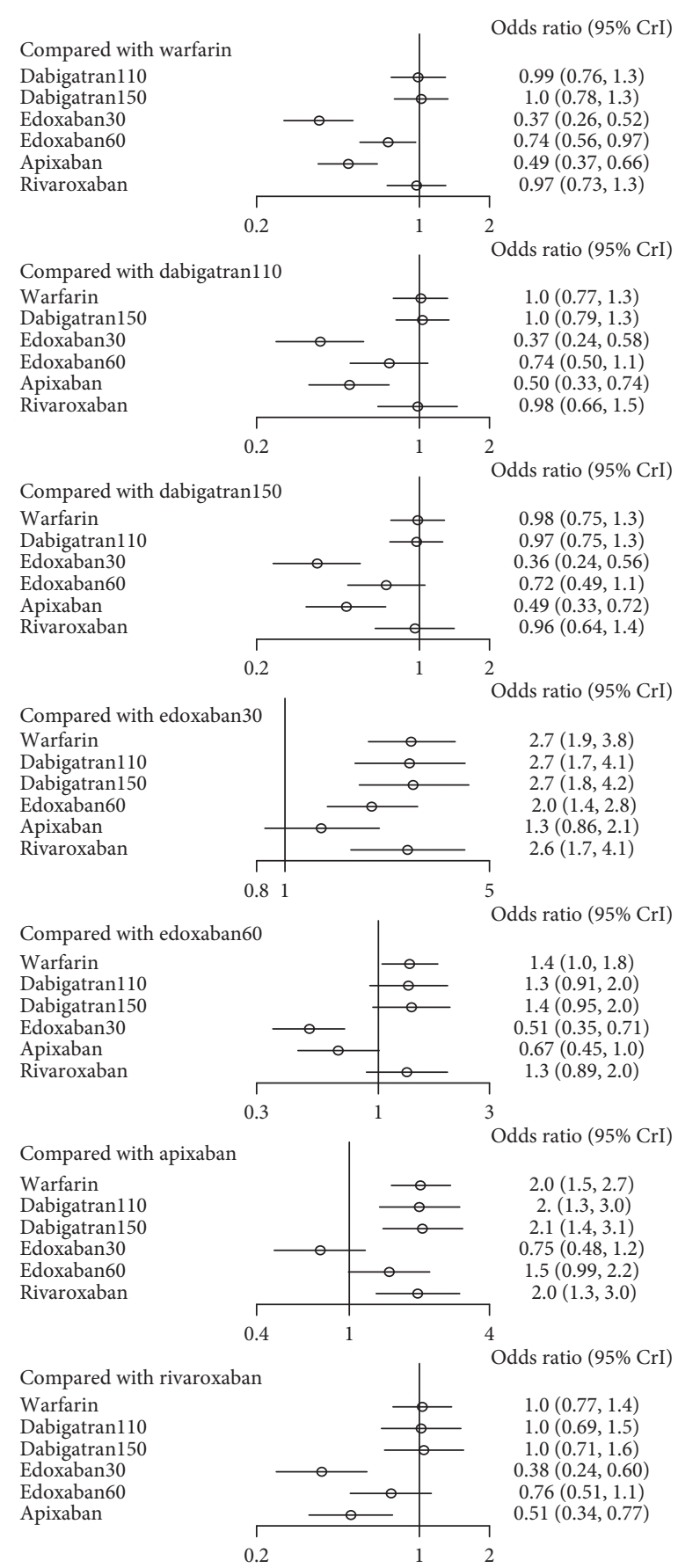

FIGURE 18: Forest plot for the safety of the comparison among different treatments of patients with moderate renal function. 


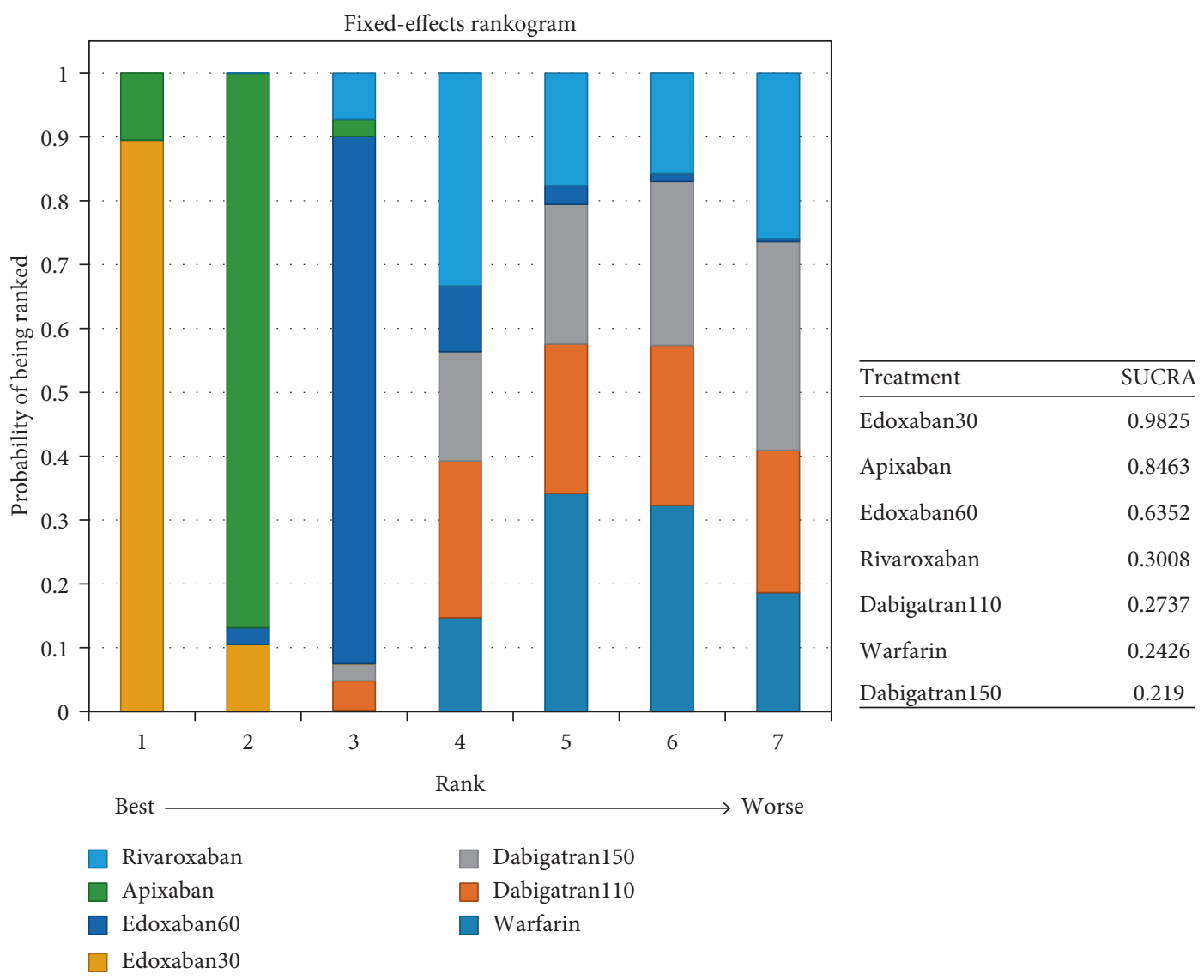

FIGURE 19: Ranking plots for the safety of the comparison among different treatments of patients with moderate renal function.

use. However, the characteristic of patients with normal renal function treated with dabigatran110 was not available owing to some limitations. Even though, these data may give a possible explanation for the results, or meant there was a high tendency for such results achieved owing to these data. Besides, apixaban was associated with the least renal extraction (27\%) [31], which may partly give an explanation for better results of patients treated with apixaban. In addition, we found that NOACs and warfarin would have an effect on the renal function, with different influence with respect to the various drugs. One article had compared the effects on renal function among NOACs and warfarin, finding that patients treated with NOACs were associated with renal function decline commonly, in spite of the lower risks of adverse renal outcomes of NOACs than warfarin [32]. However, the comparison of the effects associated with different NOACs on the renal function was unclear, meaning such effects may give a possible explanation for the results.

\section{Limitation}

Although the four RCTs identified in our analysis met the criterion better, the heterogeneity also existed as ROCKET, ARISTOTLE, and ENGAGE AF-TIMI 48 were double-blind trails, while RE-LY was open-labeled. In addition, the difference of criterion of inclusion, control of warfarin, and the definition of major bleeding should not be ignored. Besides, owing to the data collected, we could not form a closed loop for our NMA, which would have the effect on the examination of the model.

\section{Conclusion}

In patients with normal renal function, dabigatran $110 \mathrm{mg}$ (bid) might have a better effect on the clinical results. And it does not coincide with patients taking dabigatran $110 \mathrm{mg}$ with dose reduction for other factors including aged $\geq 75$ years, renal impairment (CrCL $30-50 \mathrm{~mL} / \mathrm{min}$ ), gastritis, esophagitis, or gastroesophageal reflux, receiving concomitant verapamil, and so on. For patients with mild renal impairment, apixaban $5 \mathrm{mg}$ (bid) would be a better choice for preventing stroke or systemic embolism and major bleeding, while apixaban $5 \mathrm{mg}$ (bid) and edoxaban $60 \mathrm{mg}$ (qd) were recommended for patients with moderate renal impairment. However, considering the fact of no RCTs for the head-to-head comparison, caution should be exercised over selecting each of NOACs for patients.

\section{Conflicts of Interest}

The authors have no conflicts of interest regarding the publication of this paper. 


\section{References}

[1] X. Wang, Q. Fu, F. Song et al., "Prevalence of atrial fibrillation in different socioeconomic regions of China and its association with stroke: results from a national stroke screening survey," International Journal of Cardiology, vol. 271, pp. 92-97, 2018.

[2] J.-P. Bassand, G. Accetta, W. Al Mahmeed et al., "Risk factors for death, stroke, and bleeding in 28,628 patients from the GARFIELD-AF registry: rationale for comprehensive management of atrial fibrillation," PloS One, vol. 13, no. 1, Article ID e0191592, 2018.

[3] H. Reinecke, M. Nabauer, A. Gerth et al., "Morbidity and treatment in patients with atrial fibrillation and chronic kidney disease," Kidney International, vol. 87, no. 1, pp. 200-209, 2015.

[4] Y. Pan, J. Jing, W. Chen, Y. Wang, and Y. He, "Association between impaired renal function and stroke outcome in patients with versus without atrial fibrillation," European Journal of Neurology, vol. 25, no. 8, pp. 1041-1048, 2018.

[5] A. Zirlik and C. Bode, "Vitamin K antagonists: relative strengths and weaknesses vs. direct oral anticoagulants for stroke prevention in patients with atrial fibrillation," Journal of Thrombosis and Thrombolysis, vol. 43, no. 3, pp. 365-379, 2017.

[6] S. J. Connolly, M. D. Ezekowitz, S. Yusuf et al., "Dabigatran versus warfarin in patients with atrial fibrillation," New England Journal of Medicine, vol. 361, no. 12, pp. 1139-1151, 2009.

[7] M. R. Patel, K. W. Mahaffey, J. Garg et al., "Rivaroxaban versus warfarin in nonvalvular atrial fibrillation," New England Journal of Medicine, vol. 365, no. 10, pp. 883-891, 2011.

[8] C. B. Granger, J. H. Alexander, J. J. V. McMurray et al., "Apixaban versus warfarin in patients with atrial fibrillation," New England Journal of Medicine, vol. 365, no. 11, pp. 981992, 2011.

[9] R. P. Giugliano, C. T. Ruff, E. Braunwald et al., "Edoxaban versus warfarin in patients with atrial fibrillation," New England Journal of Medicine, vol. 369, no. 22, pp. 2093-2104, 2013.

[10] P. Kirchhof, S. Benussi, D. Kotecha et al., "2016 ESC guidelines for the management of atrial fibrillation developed in collaboration with EACTS," European Heart Journal, vol. 37, no. 38, pp. 2893-2962, 2016.

[11] J. Steffel, P. Verhamme, T. S. Potpara et al., "The 2018 European heart rhythm association practical guide on the use of non-vitamin $\mathrm{K}$ antagonist oral anticoagulants in patients with atrial fibrillation," European Heart Journal, vol. 39, no. 16, pp. 1330-1393, 2018.

[12] N. Riva, W. Ageno, and A. Gatt, "Estimating renal function in patients with atrial fibrillation: which dose of direct oral anticoagulants?" Internal and Emergency Medicine, vol. 13, no. 7, pp. 1001-1004, 2018.

[13] F. Del-Carpio Munoz, S. M. Gharacholou, T. M. Munger et al., "Meta-analysis of renal function on the safety and efficacy of novel oral anticoagulants for atrial fibrillation," The American Journal of Cardiology, vol. 117, no. 1, pp. 69-75, 2016.

[14] R. Zou, J. Tao, W. Shi et al., "Meta-analysis of safety and efficacy for direct oral anticoagulation treatment of nonvalvular atrial fibrillation in relation to renal function," Thrombosis Research, vol. 160, pp. 41-50, 2017.

[15] W. Fu, H. Guo, J. Guo et al., "Relative efficacy and safety of direct oral anticoagulants in patients with atrial fibrillation by network meta-analysis," Journal of Cardiovascular Medicine, vol. 15, no. 12, pp. 873-879, 2014.
[16] G. Andò and P. Capranzano, "Non-vitamin K antagonist oral anticoagulants in atrial fibrillation patients with chronic kidney disease: a systematic review and network meta-analysis," International Journal of Cardiology, vol. 231, pp. 162-169, 2017.

[17] G. Salanti, J. P. Higgins, A. Ades, and J. P. Ioannidis, "Evaluation of networks of randomized trials," Statistical Methods in Medical Research, vol. 17, no. 3, pp. 279-301, 2008.

[18] G. Salanti, A. E. Ades, and J. P. A. Ioannidis, "Graphical methods and numerical summaries for presenting results from multiple-treatment meta-analysis: an overview and tutorial," Journal of Clinical Epidemiology, vol. 64, no. 2, pp. 163-171, 2011.

[19] D. J. Spiegelhalter, N. G. Best, B. P. Carlin, and A. van der Linde, "Bayesian measures of model complexity and fit," Journal of the Royal Statistical Society: Series B (Statistical Methodology), vol. 64, no. 4, pp. 583-639, 2002.

[20] R. M. Turner, J. Davey, M. J. Clarke, S. G. Thompson, and J. P. Higgins, "Predicting the extent of heterogeneity in metaanalysis, using empirical data from the cochrane database of systematic reviews," International Journal of Epidemiology, vol. 41, no. 3, pp. 818-827, 2012.

[21] S. P. Brooks and A. Gelman, "General methods for monitoring convergence of iterative simulations," Journal of Computational and Graphical Statistics, vol. 7, no. 4, pp. 434-455, 1998.

[22] A. J. Camm, "The RE-LY study: randomized evaluation of long-term anticoagulant therapY: dabigatran vs. warfarin," European Heart Journal, vol. 30, no. 21, pp. 2554-2555, 2009.

[23] M. D. Ezekowitz, R. Nagarakanti, H. Noack et al., "Comparison of dabigatran and warfarin in patients with atrial fibrillation and valvular heart disease," Circulation, vol. 134, no. 8, pp. 589-598, 2016.

[24] J. H. Alexander, U. Andersson, R. D. Lopes et al., “Apixaban $5 \mathrm{mg}$ twice daily and clinical outcomes in patients with atrial fibrillation and advanced age, low body weight, or high creatinine," JAMA Cardiology, vol. 1, no. 6, pp. 673-681, 2016.

[25] B. J. Geller, R. P. Giugliano, E. Braunwald et al., "Systemic, noncerebral, arterial embolism in 21,105 patients with atrial fibrillation randomized to edoxaban or warfarin: results from the effective anticoagulation with factor xa next generation in atrial fibrillation-thrombolysis in myocardial infarction study 48 trial," American Heart Journal, vol. 170, no. 4, pp. 669-674, 2015.

[26] R. De Caterina, G. Renda, A. P. Carnicelli et al., "Valvular heart disease patients on edoxaban or warfarin in the ENGAGE AF-TIMI 48 trial," Journal of the American College of Cardiology, vol. 69, no. 11, pp. 1372-1382, 2017.

[27] Z. Wolfe, S. U. Khan, F. Nasir, C. Raghu Subramanian, and B. Lash, "A systematic review and bayesian network metaanalysis of risk of intracranial hemorrhage with direct oral anticoagulants," Journal of Thrombosis and Haemostasis, vol. 16, no. 7, pp. 1296-1306, 2018.

[28] P. Verdecchia, F. Angeli, C. Bartolini et al., "Safety and efficacy of non-vitamin $\mathrm{K}$ oral anticoagulants in non-valvular atrial fibrillation: a bayesian meta-analysis approach," Expert Opinion on Drug Safety, vol. 14, no. 1, pp. 7-20, 2015.

[29] A. H. Katsanos, D. Mavridis, J. Parissis et al., "Novel oral anticoagulants for the secondary prevention of cerebral ischemia: a network meta-analysis," Therapeutic Advances in Neurological Disorders, vol. 9, no. 5, pp. 359-368, 2016.

[30] P. B. Nielsen, D. A. Lane, L. H. Rasmussen, G. Y. H. Lip, and T. B. Larsen, "Renal function and non-vitamin K oral anticoagulants in comparison with warfarin on safety and efficacy outcomes in atrial fibrillation patients: a systemic review and 
meta-regression analysis," Clinical Research in Cardiology, vol. 104, no. 5, pp. 418-429, 2015.

[31] C. Frost, J. Wang, S. Nepal et al., "Apixaban, an oral, direct factor Xa inhibitor: single dose safety, pharmacokinetics, pharmacodynamics and food effect in healthy subjects," British Journal of Clinical Pharmacology, vol. 75, no. 2, pp. 476-487, 2013.

[32] X. Yao, N. Tangri, B. J. Gersh et al., "Renal outcomes in anticoagulated patients with atrial fibrillation," Journal of the American College of Cardiology, vol. 70, no. 21, pp. 2621-2632, 2017. 